DOI: DOI: http://dx.doi.org /10.22185/24487147.2017.92.014

\title{
Determinantes del logro educativo de los migrantes en la Ciudad de México*
}

\author{
Julio Santiago-Hernández \\ Universidad de Guadalajara, México
}

Resumen

El propósito de este trabajo es analizar el efecto de la situación migratoria sobre la edad de salida de la escuela y el logro educativo. Interesa saber si las diferencias observadas se deben a su condición migratoria en si misma o bien a otras variables sociodemográficas asociadas a su posición que podrían colocar a los migrantes en situación de desventaja educativas con respecto a los nativos en la Ciudad de México. Para ello se utilizaron los datos de la Encuesta sobre Desigualdad y de Movilidad Social en la Ciudad de México, 2009. Los resultados sugieren, a diferencia de lo evidenciado por las investigaciones de la década de los setenta que suponían que las tasas de movilidad ascendente beneficiaban por igual a migrantes y nativos, que a los migrantes les va mal, aunque no por el hecho de ser migrantes, sino porque tienden a contar con menores atributos económicos, culturales y de capital social en sus familias de origen, lo que les impide obtener un mayor provecho de sus esfuerzos para lograr un desempeño educativo similar o superior al de los nativos. Otro hallazgo sugiere que incluso después de controlar el origen social desventajoso, las mujeres migrantes rurales mantienen un desempeño consistentemente desfavorable en contraste con las nativas.

Palabras clave: Migración interna, educación, mercados de trabajo, Ciudad de México.

Abstract

Determinants of educational attainment of migrants in Mexico City

The purpose of this paper is to analyze the effect of immigration status on the age at which migrants exit formal schooling and their educational attainment. The aim of this work is to identify if the observed differences are due to the immigration status itself or derived from other sociodemographic variables associated with their status, a condition that could place migrants at an educational disadvantage with respect to Mexico City natives. To further investigate, we used data from the 2009 Inequality and Social Mobility Survey of Mexico City and found out that unlike the evidence of research made in the 1970s, which assumed that upward mobility was a phenomenon present in both migrant and native individuals, migrants' educational performance is not as good as that of the natives, not just for the fact that they are migrants but because they tend to have lower economic, cultural and social capital attributes within their families of origin, a condition that prevents them from taking better advantage of their efforts to attain a similar or higher educational performance to the one of the natives. Another finding suggests that even after controlling for the disadvantageous social origin, rural migrant women maintain a consistently unfavorable performance when compared to the performance of the natives.

Key words: Internal migration, education, labor markets, Mexico City.

* Este artículo está basado en mi tesis de grado: Migración interna y búsqueda del bienestar: el logro educativo y ocupacional de los migrantes en la Zona Metropolitana del Valle de México, 1980-2009, para optar por el grado de Doctor en Ciencia social con Especialidad en Sociología, en El Colegio de México. Agradezco al Dr. Patricio Solís, por su generosa dirección. Asimismo, mi agradecimiento a la Dra. Edith Pacheco y al Dr. Gustavo Verduzco, por haber enriquecido la discusión con sus comentarios. No está demás aclarar que los errores y desaciertos que de este trabajo se deriven son exclusivamente responsabilidad mía. 


\section{INTRODUCCIÓN}

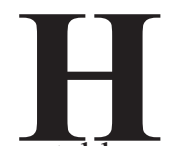

istóricamente, la Ciudad de México ha sido uno de los principales puntos de atracción de migrantes que buscan oportunidades de trabajo y un lugar donde establecerse; esto fue especialmente notable en el caso de migrantes jóvenes de origen rural y con bajos niveles de instrucción (Negrete, 1990: 647). La creciente migración de localidades rurales y de zonas atrasadas, se acompañó de una reducción en los niveles de escolaridad y falta de experiencia en trabajos no agrícolas, lo que incrementó sus desventajas en el mercado de trabajo de la ciudad con respecto a los nativos dado el aumento en los requerimientos formales para ingresar a la fuerza de trabajo (Balán et al., 1977; Muñoz et al., 1977).

Lo anterior fue una de las principales conclusiones de los estudios orientados a profundizar en el conocimiento de la migración hacia esta ciudad, los cuales dejaron claras las principales características de este proceso, al menos hasta la década de los años setenta.

Infortunadamente, hoy poco sabemos sobre las nuevas características de la migración interna hacía las grandes áreas urbanas en México, las formas emergentes de inserción en la actividad económica de los migrantes en los lugares de destino y la situación que experimentan los migrantes en su nuevo entorno, que en ocasiones no son más que un intento fallido por escapar de la pobreza extrema en sus lugares de origen.

En ese sentido, el presente trabajo busca contribuir a renovar el interés por el estudio de la migración interna a las grandes áreas urbanas del país, en particular a la Ciudad de México y su vínculo con uno de los factores más relevantes, la educación, ${ }^{1}$ que ha sido el medio principal por el cual las personas han tenido acceso a distintas posiciones ocupacionales, a partir de los datos proporcionados por la Encuesta sobre Desigualdad y Movilidad Social en la Ciudad de México (ENDESMOV 2009). ${ }^{2}$ Más específicamen-

\footnotetext{
${ }^{1}$ En este trabajo nos referimos a la educación formal que abarca desde la educación primaria hasta la educación superior y a cuyo término se obtiene un título o una certificación.

${ }^{2}$ El universo de estudio de la Encuesta sobre Desigualdad y Movilidad Social en la Ciudad de México, lo constituyeron las personas entre 30 y 60 años de edad residentes en viviendas particulares de la Zona Metropolitana de la Ciudad de México y fue levantada entre los meses de abril y agosto de 2009. El tamaño final de la muestra fue de 2038 individuos entrevistados, con proporciones similares de varones y mujeres. La encuesta tuvo un formato de historias de vida, con historias residenciales y ocupacionales completas. También incorporó información retrospectiva sobre las transiciones familiares y educativas más relevantes. Dado que el propósito principal de la encuesta era obtener información sobre la transmisión intergeneracional de la desigualdad, se levantó una batería extensa de preguntas sobre las características socioeconómicas de la familia
} 
te, el propósito de este trabajo es analizar los determinantes de la edad de salida de la escuela y el logro educativo de los migrantes a la Ciudad de México. ${ }^{3}$ Nos interesa ver si los migrantes presentan desventajas educativas con respecto a los nativos, ya sean asociadas a las desventajas en el acceso a la educación en sus comunidades de origen antes de migrar, o bien a que sus trayectorias educativas se ven truncadas más tempranamente una vez que llegaron a la ciudad. Queremos saber si, en caso de existir tales desventajas, éstas se deben directamente a la situación migratoria actual, o bien a otras características que se le asocian, como son los orígenes sociales (medido por la educación y ocupación del padre), y otras variables sociodemográficas individuales (como el sexo) y contextuales (como la cohorte de nacimiento).

Para ello, el trabajo se organizó de la siguiente manera. Además de la introducción y el anexo. En la primera parte, se reflexiona sobre los vínculos entre la migración interna, cambios económicos y los factores determinantes del logro educativo. En la segunda, se analiza la edad a la salida de la escuela a partir del análisis de supervivencia, técnica que permite contrastar las intensidades y los calendarios de hombres y mujeres según la situación migratoria. ${ }^{4}$ No obstante, debido a que dicha técnica posee algunas limitaciones que dificultan la realización de estudios más complejos, en un tercer apartado, se utiliza un modelo logístico bivariado para explorar los factores que inciden sobre la probabilidad de experimentar la salida de la escuela a lo largo del tiempo individual. En ese caso, el modelo toma la forma de un logístico de tiempo discreto, valorando la probabilidad de que una persona cambie de un estado (todavía asiste a la escuela) a otro (ya no asiste a la escuela). En la cuarta parte, para el examen de los determinantes de logro educativo se recurre primero a modelos bivariados de regresión logística ordenada por cohorte y sexo para valorar la probabilidad de que

de los padres del entrevistado, lo cual provee información que no está disponible en las encuestas sociodemográficas habituales (Solís, 2012).

${ }^{3}$ A lo largo del trabajo se utiliza el término Ciudad de México para referirse a la Zona Metropolitana de la Ciudad de México según la definición hecha en la encuesta que incluye al Distrito Federal y 25 municipios del Estado de México (Acolman, Atizapan de Zaragoza, Chalco, Chiautla, Chicoloapan, Chiconcuac, Chimalhuacán, Coacalco de Berriozábal, Coyotepec, Cuautitlán, Cuautitlán Izcalli, Ecatepec de Morelos, Huixquilucan, Ixtapaluca, La Paz, Naucalpan de Juárez, Nezahualcóyotl, Nicolás Romero, Tecámac, Tepotzotlán, Texcoco, Tlalnepantla de Baz, Tultepec, Tultitlán y Valle de Chalco Solidaridad).

${ }^{4}$ En adelante cuando se mencione el término "a la salida de la escuela" nos estaremos refiriendo a una de las transiciones más importantes hacia la vida adulta. Puede obedecer al egreso escolar o al abandono de los estudios. "En el primer caso el alumno concluye con su escolaridad porque llegó al nivel que deseaba o al grado máximo al que aspiraba o al que su sociedad esperaba de él. En el segundo caso el estudiante deserta de la escuela en algún momento, ya sea al concluir un grado o un nivel escolar, e incluso durante el ciclo escolar, esgrimiendo para ello argumentos tan variados como las cuestiones económicas, los problemas familiares, los embarazos no planeados, o la desmotivación escolar, entre otras razones" (Pérez, 2012: 701). 
un individuo obtenga un nivel educativo mayor que otro individuo en el tiempo. Posteriormente, se utilizan modelos de regresión logística multivariados para ver si el efecto de la migración persiste una vez controladas otras características socioeconómicas de las personas, principalmente aquellas relacionadas al origen social. Finalmente, se presentan algunas consideraciones finales producto de los hallazgos más relevantes de este trabajo.

\section{MigRACión Y EDUCACIÓN}

En las sociedades modernas la educación formal es el medio principal por el cual las personas logran acceso a las distintas posiciones ocupacionales. Los títulos o grados otorgados por la escuela sirven como "credenciales" que certifican un cierto nivel de entrenamiento y además garantizan que las personas que los poseen tengan las características individuales "adecuadas" (Balán, 1969). De hecho, hasta la segunda mitad del siglo pasado, ${ }^{5}$ la educación jugó un rol importante en los procesos de movilidad social en nuestro país, así lo ha argumentado Solís:

La educación no sólo representaba una oportunidad para ingresar a nuevos mundos por medio del acceso a la cultura y al conocimiento, sino que además adquirió mayor importancia en el mundo del trabajo debido a las demandas crecientes de trabajadores capacitados asociadas a la expansión industrial (Solís, 2007: 85).

En este contexto, la educación sé volvió un factor relevante en el proceso de toma de decisiones de migrar, ya que los individuos que poseían un mayor nivel de instrucción asimilaron de mejor manera la información, al percibir mejor las oportunidades de empleo en otras regiones y por ende conseguir mayores posibilidades de éxito, de lo cual se derivó una mayor propensión a migrar. El propio sistema educativo también fuerza a moverse hacia las ciudades a las personas que desean continuar sus estudios, además, debido a que el tipo de educación que reciben está más enfocado a actividades de carácter urbano, los incide a residir en ellas.

En el caso de la Ciudad de México que ha sido uno de los principales puntos de atracción para los migrantes que buscaban oportunidades de trabajo; fue especialmente notable desde mediados del siglo pasado un proceso de marginalización ocupacional creciente debido, en parte, al deficiente

\footnotetext{
${ }^{5}$ Recientemente, se ha presentado evidencia sobre los rendimientos decrecientes de la escolaridad en el mercado de trabajo, particularmente en los niveles de educación superior (Díaz, 1995: ANUIES, 1996, Muñoz, 1996).
} 
nivel de instrucción con que llegaron a la ciudad proporciones importantes de migrantes jóvenes que provenían principalmente de localidades rurales y de zonas atrasadas, ampliando la brecha en los niveles de instrucción de los migrantes que vivían en la capital y la de los nativos de la misma y que, por tanto, estimularon a que disminuyera su grado de competitividad en términos de oportunidades ocupacionales, dado el aumento en los requerimientos formales para ingresar a la fuerza de trabajo (Stern, 1977: 101).

Habrá que explorar la validez actual de éste y otros planteamientos ante las condiciones que hoy enfrentan la Ciudad de México y el país en general. Máxime que la ciudad mantiene una situación privilegiada en relación con el resto del país en lo que se refiere a los niveles de desarrollo socioeconómico y los indicadores demográficos. Que se han visto reflejados en el ámbito de la oferta educativa que no sólo es cuantitativamente amplia, sino además cualitativamente diversa, particularmente en los niveles medio superior y superior. Además, la Ciudad de México se ha convertido en sede principal de algunas de las instituciones de educación superior de mayor prestigio en el país, tanto pública como privada (Blanco et al., 2014). No obstante, la ciudad es también un espacio marcado por amplias desigualdades educativas, que se manifiestan en la diversificación de las trayectorias educativas y en la estratificación de los niveles de logro, como se verá más adelante. Antes, se presenta de manera sucinta la evolución del fenómeno en las últimas décadas con el objeto de contextualizar el objeto de estudio.

\section{La migración a la Ciudad de México}

El acelerado crecimiento de las ciudades en México, al igual que en toda América Latina, se debió en buena medida a la migración rural-urbana que algunas veces superó el crecimiento natural de la población de las ciudades. En México fue la capital del país la que captó el mayor número de inmigrantes ya que desde la década de 1940 se convirtió en un fuerte polo de atracción de población rural empobrecida (Romer, 2009; Corona y Luque, 1992).

El dinámico desarrollo industrial y de servicios creó un mercado de trabajo en constante crecimiento que alcanzó las tasas medias anuales de siete y 7.6 por ciento para hombres y mujeres, respectivamente, brindando estímulos a las migraciones internas. Esta oferta de empleos sufrió un descenso considerable en los decenios posteriores: en el de 1950 fue $4.9 \mathrm{y}$ cinco por ciento y en el de 1960, 3.2 y 3.3 por ciento (Contreras, 1972). Estos cambios en el empleo se debieron en gran parte a las transformaciones que ocurrieron en la estructura industrial desde mediados de los cincuenta. En 
esta época se dio inició a la política sustitutiva de bienes de capital mediante la cual se incrementaron las importaciones y la utilización de tecnología intensiva en capital, lo que trajo como consecuencia la reducción de la demanda de mano de obra (Oliveira, 1977).

Si bien en la década de 1940 los importantes flujos migratorios hacia la capital respondían a una atracción real que se reflejaba en las oportunidades de empleo y mejor salario, en los decenios posteriores la intensificación de la migración ocurrió al margen de la demanda de mano de obra y reflejó básicamente el desempleo y el subempleo en la agricultura, resultado de una profunda crisis que atravesaba el sector (Muñoz et al., 1977: 131). En efecto, se observó una intensificación del flujo migratorio en las décadas de 1960 y 1970 a pesar de la constante disminución de las oportunidades de empleo.

Entre 1940 y 1970, la Ciudad de México había recibido aproximadamente 50 por ciento de los migrantes de todo el país y la mayor intensidad del flujo migratorio se registró en el decenio de 1960. En 1970, más de la tercera parte de los ocho millones de habitantes con los que contaba la ciudad eran inmigrantes (Stern, 1977: 115). Este sólo hecho da cuenta de la importancia del fenómeno migratorio en 1970, que se advertía aún más si se tomaba en cuenta que alrededor de 54 por ciento de la población económicamente activa (PEA) masculina de 21 a 60 años estaba constituida por fuerza de trabajo inmigrante (Muñoz et al., 1977). Esta masa de trabajadores logró integrarse en mayor medida al sector secundario - de manera más específica en las industrias que fabrican bienes de producción-que en otras ramas del sector terciario, incluidos los servicios personales que tuvieron un peso importante en la demanda de mano de obra (Muñoz et al., 1977).

Si bien, hasta la década de 1970 los migrantes tuvieron la posibilidad de integrarse al mercado de trabajo en ocupaciones con cierta seguridad laboral, los inmigrantes de las décadas posteriores, sobre todo de origen rural y bajos niveles educativos, cuya experiencia se limitaba de manera predominante a la agricultura, quedaron más afectados por la pobreza (marginalidad urbana). Su integración al sector manufacturero implicó salarios más bajos mientras que muchos otros no lograron integrarse, lo que los orilló al subempleo (o desempleo) disfrazado con remuneraciones por debajo del salario mínimo establecido (Muñoz et al., 1977: 129, 220).

Aunado a lo anterior, el ritmo acelerado de concentración espacial de la población, en combinación con el desarrollo del sector industrial y la actividad económica de la Ciudad de México, terminaron por modificar 
el patrón observado (al menos hasta finales de los años setenta) de redistribución espacial de los mexicanos, como consecuencia de diversos factores relacionados con problemas propios del enorme tamaño de la urbe: la segregación y marginación urbana de una gran cantidad de personas que no pudieron ser absorbidas por las economías urbano industriales, la creciente informalización del trabajo, el aumento del costo de los principales servicios urbanos (agua potable, alcantarillado, etc.), la escasez de vivienda, la inseguridad pública, la contaminación ambiental y problemas para satisfacer la demanda de servicios de salud, educación y unidades de esparcimiento (Browning y Corona, 1995).

De tal suerte que a finales de la década de los años setenta llega a su agotamiento, de manera eminente, el modelo industrializador aplicado en el país. La crisis económica y social a inicios de los ochenta, marcó una nueva etapa del crecimiento de la ciudad, en donde las actividades industriales y la población se desconcentraron hacia las localidades del Estado de México, como resultado de la nueva política de reindustrialización y liberalización económica que perseguía la conformación de un sector industrial articulado con el resto de la economía y especializado con el comercio internacional, propiciando cierta diversificación territorial de las actividades productivas, un crecimiento acelerado de los centros urbanos secundarios aledaños y un proceso de terciarización de la economía del Distrito Federal (Garza, 2003).

Quizá el cambio más importante fue la modificación de su comportamiento histórico de ser el principal centro receptor de población del país, en la década de los ochenta, se convierte en el principal expulsor de población (Corona et al., 1999). Los datos censales indicaron que durante el quinquenio de 1975-1980 la Ciudad de México alcanzó un saldo neto migratorio positivo cercano a las 105 mil personas, lo cual implicó una tasa media de migración neta del orden de 0.7 por ciento. En contraste, para el quinquenio 1985-1990 la situación fue diferente, la inmigración disminuyó, en tanto que la emigración casi duplicó su magnitud, ${ }^{6}$ tornando negativa a la tasa de migración neta con un valor cercano a -1.9 por ciento (Camposortega, 1992). ${ }^{7}$ Para el primer lustro de los noventa, ${ }^{8}$ los datos del

\footnotetext{
${ }^{6}$ Según la información censal, durante el quinquenio 1985-1990 la situación migratoria de la zona fue la siguiente 425361 personas mayores de cinco años cambiaron su residencia del interior de la república a la Ciudad de México, en tanto que el número de los emigrantes fue de 716 224 personas, lo que representó un saldo migratorio negativo de 290863 personas.

${ }^{7}$ En el quinquenio 1985-1990 llegaron a la ciudad 80 hombres por cada 100 mujeres, situación que puede encontrar su explicación en la mayor inserción laboral femenina en actividades terciarias (Corona et al., 1999).

${ }^{8}$ Llegaron aproximadamente 692 mil personas y salieron 638 mil, lo que se tradujo en un saldo positivo de 53 mil, que representó una tasa de migración de 0.3 por ciento (Corona et al., 1999).
} 
Conteo de 1995 mostraron una relativa recuperación de su balance migratorio, que fue confirmada por el XII Censo General de Población y Vivienda que reveló que la Ciudad de México recuperaba su balance migratorio para llegar prácticamente a cero en el periodo 1995-2000, ${ }^{9}$ tendencia que ha continuado hasta el quinquenio más reciente de 2005-2010, según datos censales. ${ }^{10}$

Uno de los principales aspectos que muestran los cambios ocurridos en la migración de los años ochenta y noventa, es que el origen geográfico de los migrantes ha variado poco, lo que ha cambiado es la importancia relativa de cada una de las entidades de origen. ${ }^{11}$ De igual forma las características sociodemográficas de la población inmigrante en la Ciudad de México han experimentado pocos cambios, continuó llegando población con bajos niveles de escolaridad, que se ubicaron principalmente en el sector terciario, en el trabajo informal o en el empleo doméstico. Una diferencia importante de los años noventa con la década anterior, es el cambio de predominio femenino por el masculino. ${ }^{12}$ Respecto a la estructura por edad, los inmigrantes menores de 15 años representaron 20 por ciento de la población que llegó en el quinquenio 1990-1995, mientras que la población de 15 a 34 años de edad representó 61 por ciento. Esto significó que aproximadamente 80 por ciento de la población inmigrante tenía menos de 35 años, lo que sugería una migración predominantemente laboral (Corona, Chávez y Gutiérrez, 1999).

El conjunto de estos elementos muestra que la migración de la población a la Ciudad de México es una expresión del reacomodo de los habitantes de medianos o pocos recursos en busca de mejores oportunidades y mejor calidad de vida. Habrá que explorar los determinantes y patrones de logro educativo de los migrantes a la Ciudad de México, con el fin de evaluar hasta qué punto la migración a la principal aglomeración urbana del país representa una alternativa de logro educativo o bien representa un

\footnotetext{
${ }^{9}$ Llegaron aproximadamente 517 mil personas y salieron 549 mil, lo que se tradujo en un saldo negativo de 32 mil (Pérez, 2005).

${ }_{10}$ Según datos censales de 2010, llegaron aproximadamente 891 mil personas y salieron 680 mil, lo que se tradujo en un saldo positivo de de 210, 767 personas en el periodo de referencia.

${ }_{11}$ De acuerdo con los datos censales del periodo 1975-1980, 1985-1990, 1990-1995 y 19952000, las entidades que enviaban más población a la Ciudad de México eran Puebla, Veracruz, Oaxaca, Hidalgo, Guerrero, Michoacán, Guanajuato, Jalisco y los municipios conurbados del Estado de México. Durante el primer lustro de los noventa estas nueve entidades enviaban 83 por ciento de los inmigrantes de la zona, es decir, que cuatro de cada cinco provenían de ellas (Corona et al., 1999).

${ }^{12}$ Mientras que en el segundo quinquenio de los ochenta por cada 100 mujeres que llegaban lo hacían 80 hombres, en el primer lustro de los noventa por cada 100 mujeres que inmigraron lo hicieron 130 hombres (Corona et al., 1999).
} 
paso a condiciones de desventaja y marginación permanente (Santiago, 2015).

\section{Particularidades de la EDAD A la PRimera SAlida de la ESCUEla}

La edad a la salida de la escuela es uno de los eventos más importantes en la transición a la vida adulta pues denota el fin de un período inicial de entrenamiento, en la medida en que involucra la adquisición de capacidades, competencias cognitivas y habilidades para enfrentar con mayor preparación los roles y responsabilidades adultas, como son el inicio de la vida laboral y el matrimonio entre otros. El sistema educativo se ha convertido en la principal fuente de socialización, sobre todo para las mujeres, quienes en los últimos 30 años se han incorporado masivamente al sistema educativo en la mayoría de los países (Lloyd et al., 2005; Lloyd, 2006). En el mundo, a finales de la década de los noventa, el acceso al sistema educativo sobre todo en zonas rurales, se incrementó en todos los países - excepto en algunas zonas del oeste africano. El aumento más significativo se produjo en el acceso a la primaria, lo cual constituye un logro debido al aumento de la población que asiste a la escuela (Lloyd et al., 2005; Lloyd, 2006, UNESCO, 2009). No obstante, hablar de escolaridad implica ir más allá del acceso al sistema educativo; ya que la permanencia dentro del mismo es un factor esencial para explicar la transición a la adultez (Billari y Philipov, 2004; Hofferth et al., 2001; Lloyd et al., 2005; Echarri y Pérez, 2007).

En un país como México y en particular su principal metrópoli, donde la institucionalización del curso de vida, es en el mejor de los casos parcial o segmentada (Solís, 1997), se podría esperar una mayor heterogeneidad en la edad a la primera salida de la escuela, pues ésta dependería en buena medida de los orígenes sociales de los individuos, así como de las diferencias entre hombres y mujeres. Dichas diferencias en la edad de salida de la escuela serían, por tanto, un indicador de la brecha de oportunidades educativas que existe entre los individuos de diferentes estratos sociales. Es por esto que resulta importante revisar las diferencias en el calendario de la salida de la escuela, con especial énfasis en aquellas que se asocian a la situación migratoria, que son el objeto principal de este trabajo.

La Tabla 1 muestra los indicadores del calendario de la edad a la primera salida del sistema educativo de acuerdo a la situación migratoria $\left(1-\mathrm{S}_{\mathrm{x}}\right)$, se trata de un indicador de calendario que valora la proporción de personas que salieron por primera vez de la escuela a los 15 años de edad. Cuartil (Q), edad o duración en la cual 25, 50 y 75 por ciento de la población interrumpe por primera vez sus estudios. A partir de los cuartiles se puede 
obtener una cuarta medida, llamada rango intercuartil, que es el número de años que demora para que la primera salida de la escuela pase de constituir 25 a 75 por ciento de la población total del grupo en cuestión (Solís, 2008).

En general, los resultados confirman algunas diferencias según la situación migratoria, particularmente entre la población socializada fuera de la Ciudad de México, en especial los de origen rural que exhiben un calendario más joven de salir de la escuela frente a los socializados en la ciudad. En particular, la población migrante de primera generación muestra una mayor proporción de personas que habían salido a los 15 años en relación con los de la segunda generación y los nativos (49.25, frente a 19.40 y 14.3 por ciento, respectivamente). ${ }^{13}$ Igualmente, la edad mediana es menor para los socializados fuera que para los socializados dentro de la Ciudad de México (15 años para los de la primera generación rural y 14 años para la urbana, frente a 18 años de los de la segunda generación y los nativos, respectivamente). La edad al primer cuartil y al tercer cuartil presenta tendencias más consistentes, la edad a la salida de la escuela en ambos casos es menor para los socializados fuera de la ciudad, particularmente para los rurales. Lo anterior es consistente con lo evidenciado por trabajos, como el de Echarri y Pérez (2007) cuando comparan a jóvenes mexicanos de orígenes rurales y urbanos encuentran que la proporción de jóvenes con orígen rural que dejaron la escuela antes de los 15 años es casi 25 puntos porcentuales mayor que sus símiles urbanos, congruente con la mayor extensión de la matrícula escolar en las localidades urbanas.

Ahora bien, si por ejemplo comparamos los porcentajes de salida de la escuela a los 15 años de edad de acuerdo con la ocupación del padre (Tabla 1) es posible observar que entre los hijos de padres con ocupaciones manuales bajas la proporción de individuos que habían salido de la escuela a los 15 años era de 34.5 por ciento; en contraste entre los hijos de padres con ocupaciones no manuales altas e intermedias disminuye alcanzando cerca de cinco por ciento. Estas diferencias se confirman observando los cuartiles, por ejemplo, la edad mediana para los hijos de padres con ocupaciones no manuales altas e intermedias es de 23 años, frente a 16 años de los hijos de padre con ocupaciones manuales bajas.

Al comparar los niveles de educación del padre se puede observar una relación inversa con los porcentajes de salida de la escuela a los 15 años. Los hijos de padres con bajos niveles educativos exhiben un mayor por-

${ }^{13}$ El porcentaje de personas que habían salido a los quince años incluso es mayor al de los inmigrantes de primera generación urbanos con 37.99 por ciento. 
Determinantes del logro educativo de los migrantes en la Ciudadde Mexico / J. SANTIAGO-HERNÁNDEZ

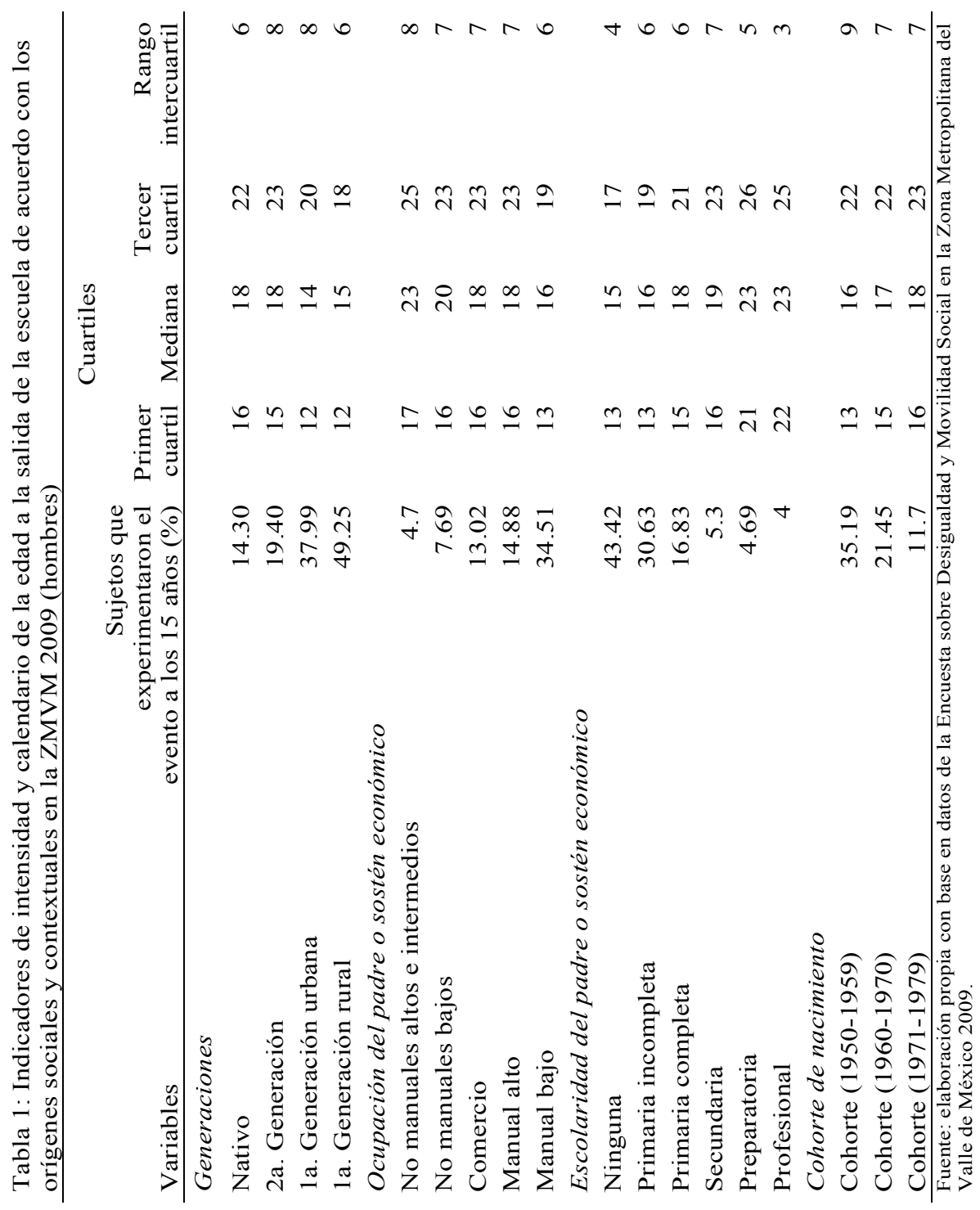


centaje de salida, confirmando la importancia del estatus socioeconómico de la familia de origen en las oportunidades educativas. Por ejemplo, el porcentaje de salida a los 15 años del sistema educativo para los hijos de padres con educación superior respecto a los hijos de padres sin educación es substancial (cuatro frente a 43.4 por ciento, respectivamente). De igual forma, la edad a los diferentes cuartiles es más tardía para los hijos de padres con escolaridad superior, además presentan el menor rango intercuartil de todos los grupos considerados, es decir, una mayor homogeneidad a la edad de salida de la escuela; por ejemplo, mientras la edad mediana para los que tuvieron padres sin instrucción es de (15 años) con una desviación de cuatro años, para aquellos que sus padres alcanzaron un nivel educativo superior es de (23 años) con una dispersión de tres años.

En el caso de las cohortes de nacimiento los resultados sugieren que los nacidos en la cohorte (1950-1959) tienden a salir de la escuela más jóvenes que los nacidos en la cohorte más reciente (1971-1979). ${ }^{14}$ En la primera cohorte (1950-1959) la personas que abandonaron el sistema educativo a los quince años alcanzaban un poco más de 32 por ciento, porcentaje que se reduce en la siguiente cohorte (1960-1970) a 21.5 por ciento y después para la cohorte más reciente (1971-1979) la disminución es más drástica a casi 12 por ciento, es decir, el cambio es reciente. Por otro lado, el análisis de los cuartiles muestra un incremento en la edad mediana para la salida del sistema educativo a través del tiempo, al pasar de 16 años en los nacidos en la cohorte más antigua a 18 años para los nacidos en la cohorte más reciente.

Es posible que las diferencias se deban a los procesos de universalización en el acceso a la educación pública iniciados en México a partir de la década de los años 1970 que han sido sumamente exitosos en términos de cobertura. Lo anterior, aunado a programas sociales que incentivan la participación escolar de individuos con bajos recursos, generando un crecimiento más que considerable en las proporciones de hombres y mujeres

\footnotetext{
${ }^{14}$ Se debe tener presente para esta parte del análisis que la vivencia de cada cohorte reflejará un periodo específico del cambio económico y social experimentado por el país y la propia Ciudad de México durante los últimos 50 años, por lo que los cambios entre cohortes muestran los efectos de estas transformaciones en la proporción de salida de la escuela a las distintas edades por cohorte. "En las cuatro décadas que transcurrieron entre 1940 y 1980, el país experimentó un acelerado proceso de industrialización y urbanización. Luego, durante los años ochenta, el agotamiento del modelo de desarrollo basado en la sustitución de importaciones derivó en una profunda crisis económica, que produjo un incremento marcado de la pobreza y redujo los niveles de bienestar de la población. Más tarde, a finales de los ochenta, las medidas de liberalización económica se acompañaron de cierta reactivación del crecimiento económico, aunque éste tuvo un ritmo bastante menor al observado antes de la década perdida de los ochenta" (Solís, 2005: 43). Además, del hecho de que la crisis de 2008 afecto y se reflejó en 2009.
} 
que han asistido a la escuela, así como un aumento en los niveles de escolaridad promedio en la población de generaciones recientes (Muñóz, 2006). ${ }^{15}$

Hasta aquí se ha hecho referencia exclusivamente al calendario de salida de la escuela de los varones. En lo que concierne al calendario de la salida de la escuela de las mujeres, se puede apreciar una mayor intensidad en la salida de la escuela (en general se mantienen las diferencias entre las socializadas fuera o dentro de la Ciudad de México, donde las primeras presentan una menor proporción de permanencia en el sistema educativo).

La Tabla 2 muestra los cuartiles de la edad a la cual el evento se experimentó. En general las socializadas fuera de la Ciudad de México, presentan una permanencia menos prolongada en el sistema educativo que las socializadas dentro de la ciudad. Sin embargo, respecto a los varones el calendario de las mujeres es más temprano, es decir, las mujeres presentaron un mayor riesgo de abandonar los estudios a edades más tempranas que los varones. En el caso de las nativas la proporción que había salido de la escuela a los 15 años fue de casi 20 por ciento, entre los varones alcanzó un poco más de 14 por ciento. De igual forma, mientras las mujeres de primera generación rural que habían experimentado la salida de la escuela a los 15 años llegaron a 60 por ciento, sus similares varones alcanzaron 49 por ciento. Igualmente, la edad mediana es menor para las migrantes de primera generación rural que para sus similares varones (13 años frente a 15 años, respectivamente). La edad al primer cuartil y la edad en el tercer cuartil siguen el mismo comportamiento. Lo anterior es consistente con lo evidenciado por Gandini y Castro (2006), quienes destacan que el calendario de las mujeres sigue siendo mucho más temprano que el de los varones, aunque señalan que las mujeres más jóvenes permanecen más tiempo en la escuela que sus antecesoras.

En lo que concierne a los orígenes sociales por educación y ocupación del padre o sostén económico, se sigue comprobando al igual que entre los varones que las hijas de padres con bajos niveles educativos exhiben un mayor porcentaje de salida, contrario a las hijas de padres con mayor nivel educativo, reafirmando la importancia del estatus socioeconómico familiar en las oportunidades educativas de las mujeres. De igual forma, las hijas de padres con ocupaciones manuales bajas muestran un mayor porcentaje de salida, en oposición a las hijas de padres con ocupaciones no manuales

\footnotetext{
${ }^{15}$ Los requerimientos educativos del mercado laboral actual son mayores, lo cual ha provocado un desplazamiento ascendente en los requisitos educativos necesarios para ingresar al mundo del trabajo de una manera relativamente ventajosa. Esto es, con cada vez mayor frecuencia alcanzar niveles de escolaridad que antes eran considerados suficientes para ingresar al mundo del trabajo en posiciones favorables, ahora resulta menos útil (Villagómez, 2008: 45).
} 
altas e intermedias. No obstante, las mujeres presentan un mayor riesgo de abandonar los estudios a edades más tempranas que los varones sobre todo en los casos en que los padres poseen los menores niveles educativos y se encuentran posicionados en empleos manuales. Llama la atención que en el caso de los orígenes ocupacionales - en todas las ocupaciones de los padres - las mujeres presentan una mayor proporción en la salida de la escuela a los 15 años que los varones y en la educación sólo hasta antes de la preparatoria, después de ésta, las mujeres se comportan a la inversa (Tabla 2). ${ }^{16}$

Las diferencias por cohortes son manifiestas, conforme son más recientes, el calendario de la transición analizada es más tardío para las mujeres y, aún más para los hombres. En la primera cohorte (1950-1959) las mujeres que abandonaron el sistema educativo a los quince años alcanzaban casi 47 por ciento, frente a 35 por ciento de los hombres, porcentaje que se reduce drásticamente para la cohorte $1960-1970$, a 30 por ciento para las mujeres y un poco más de 21 por ciento para los varones. Para caer aún más en la cohorte más reciente (1971-1979) con 17 por ciento para las mujeres y casi 12 por ciento de la población masculina, es decir, se cierra la brecha en el calendario de salida de la escuela entre hombres y mujeres, muy probamente debido al crecimiento y al propio desarrollo experimentado por el país, particularmente en materia educativa del cual las mujeres se han beneficiado en las últimas décadas. Lo anterior se confirma en el análisis de los cuartiles que muestran un incremento en la edad mediana a la salida de la escuela, aunque ésta se produce a menor ritmo para las cohortes más jóvenes, particularmente en el caso de las mujeres, donde no hubo un incremento. ${ }^{17}$

\footnotetext{
${ }^{16}$ En un trabajo donde se comparan tres generaciones de mujeres mexicanas: 1946-1950, 19511955 y 1966-1970, Conapo (2000) encuentra que los jóvenes cuya madre no asistió a la escuela o no terminó la primaria abandonan sus estudios a una edad mucho más temprana que quienes tienen una madre con escolaridad de primaria completa o más. Entre los primeros también se advierte la presencia de diferencias de género, ya que las hijas abandonan la escuela más temprano que los hijos; en cambio tales diferencias no se perciben cuando las madres son más educadas. Aunque en el análisis de Conapo se utiliza la educación de la madre como aproximación a la situación socioeconómica de la familia de origen, sus conclusiones siguen siendo válidas para un trabajo como este.

${ }_{17}$ Gandini y Castro (2006) han atribuido el cierra de la brecha en el calendario de salida de la escuela entre hombres y mujeres a los avances que en términos de asistencia y obligatoriedad escolar se fueron experimentando a partir de la década de los treinta en México y que se hacen mucho más visibles de la década de los cincuenta en adelante, de ahí que las diferencias en cuanto al calendario de la transición parezcan paulatinos en las diferencias inter-cohorte entre las generaciones antiguas y sean más marcados en el caso de la generación de los sesenta particularmente entre los varones.
} 
Determinantes del logro educativo de los migrantes en la Ciudadde Mexico / J. SANTIAGO-HERNÁNDEZ

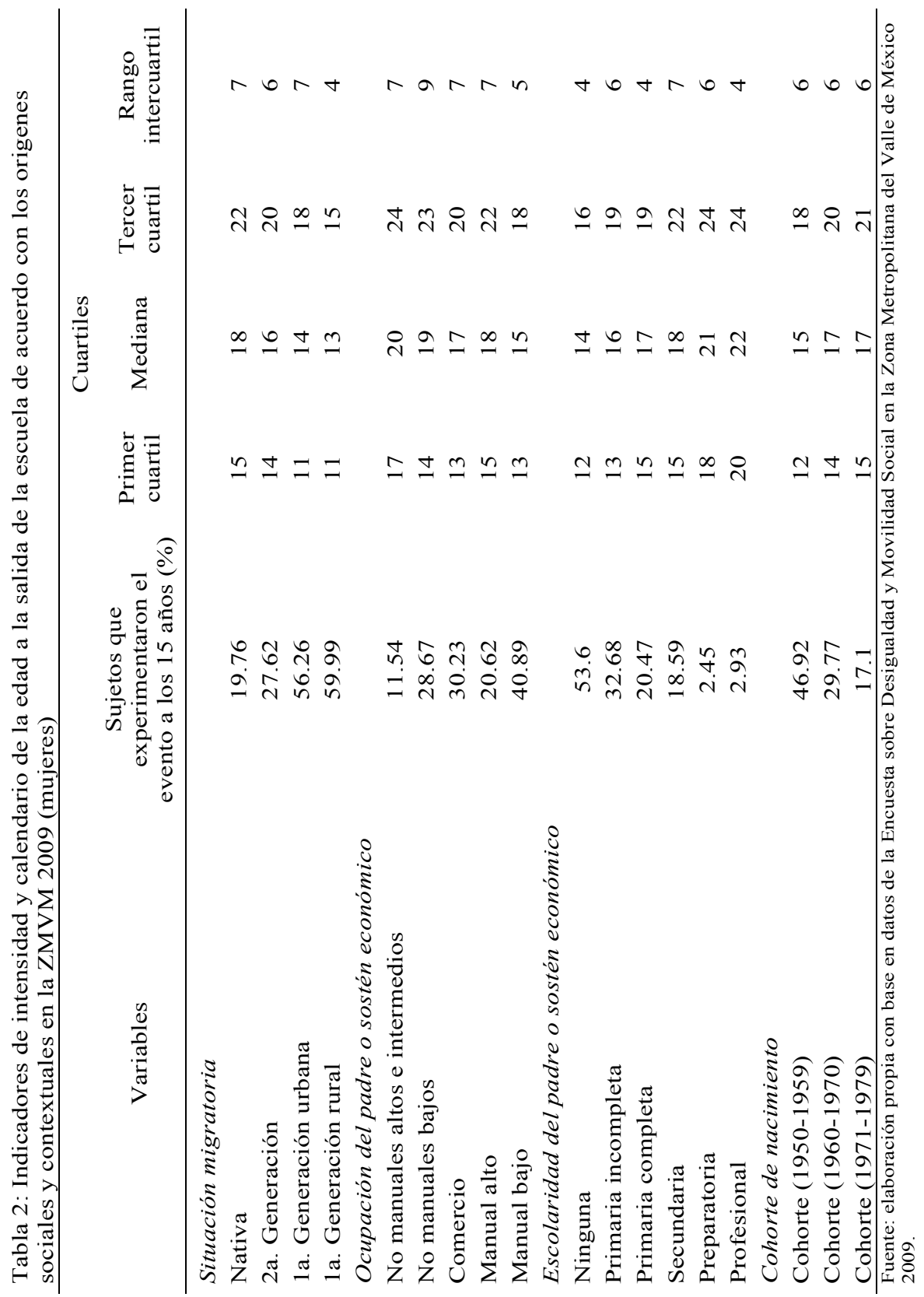


El análisis del calendario del retiro de la escuela realizado en este apartado, al explorar los efectos de las variables en forma individual, posee algunas limitaciones que dificultan la realización de estudios más complejos pues podría inducir a errores derivados de la falta de control de otras variables. En estas circunstancias, el paso natural es el ajuste de modelos multivariados (Solís, 2007).

\section{Determinantes de la SALIDA DE LA ESCUEla POR SEXO}

En la sección anterior, se sugirió que la edad a la salida del sistema educativo de los migrantes está fuertemente influenciada por los orígenes sociales. No obstante, el análisis del calendario de la salida de la escuela a partir de los indicadores descriptivos no permite saber si las diferencias en la salida de la escuela se producen por el efecto directo de la situación migratoria o son producto de otras variables asociadas, como el origen social y otras características sociodemográficas individuales y contextuales. Lo anterior sólo se consigue por medio de un modelo multivariado que permita valorar de forma adecuada el efecto independiente de cada variable en la probabilidad de salir de la escuela.

En esta sección se presenta un modelo logístico de tiempo discreto para explorar los factores que inciden sobre la probabilidad de experimentar la salida de la escuela. ${ }^{18}$ La variable dependiente se refiere a si el individuo experimentó (1), o no experimento (0), la salida de la escuela. Como variables independientes se incluyen la situación migratoria, la ocupación y escolaridad del padre, así como la cohorte y la edad. Los años-persona en riesgo de experimentar la salida de la escuela se incluyen en el modelo cómo una variable dummy de cuatro categorías: la primera categoría se define de los seis a diez años de edad (6-10); la segunda categoría de once a quince años (11-15); la tercera categoría de dieciséis a veinte años (16-20); y la última de los veintiuno a los veintinueve años (21-29) (Anexo). Con lo anterior se asume que la probabilidad de ocurrencia del evento no varía al interior de cada categoría, pero sí entre categorías.

Los resultados para los varones se presentan en la Tabla 3. Los modelos uno a seis presentan las razones de momios no ajustadas, esto es, aquellas que se obtienen de ajustar modelos en donde cada variable es introducida

\footnotetext{
${ }^{18}$ Dado que se cuenta con la historia educativa de los individuos se puede identificar exactamente los años en los que el individuo permaneció en el sistema educativo, así como el año en que salió de la escuela (esto es si experimento la transición de interés). En este sentido, la unidad de análisis son los años persona que corresponden a los años en que el individuo permaneció en el sistema educativo, es decir, se tendrá tantas observaciones para un individuo como años haya permanecido en el sistema educativo. La variable dependiente es de tipo binario y asume el valor de 0 si el individuo no salió de la escuela en el año en cuestión y 1 si salió en el año en cuestión.
} 
como variable independiente única. En general, la mayoría de los coeficientes son significativos, indicando la asociación ya descrita entre las distintas variables independientes y la salida de la escuela.

Tabla 3: Modelo de tiempo discreto para la primera salida de la escuela para los hombres. Razones de momios derivadas de los modelos logísticos binomiales (ajuste de los modelos logísticos de tiempo discreto hasta los 29 años de edad)

\begin{tabular}{ccc}
\hline Salida de la escuela & Modelo \\
ajustado
\end{tabular}

\begin{tabular}{lllllllll}
\hline Variables & 1 & 2 & 3 & 4 & 5 & 6 & 7 \\
\hline
\end{tabular}

Generaciones de inmigrantes

Nativa (ref.)

2a. Generación

1.01

$0.83 \mathrm{~b}$

1a. Generación urbana

$1.27^{\mathrm{c}}$

1.31

1a. Generación rural

$1.37^{\mathrm{c}}$

Ocupación del padre o sostén económico

No manuales altos e intermedios (ref.)

No manuales bajos

$\begin{array}{lr}1.13^{\mathrm{c}} & 1.12 \\ 1.20^{\mathrm{c}} & 1.11 \\ 1.22^{\mathrm{c}} & 1.07 \\ 1.48^{\mathrm{c}} & 1.36^{\mathrm{c}}\end{array}$

Comercio

Manual alto

Manual bajo

Escolaridad del padre o sostén económico

Ninguna (ref.)

Primaria incompleta

$0.90^{\mathrm{c}}$

$0.77^{\mathrm{a}}$

Primaria completa

$0.79^{\mathrm{c}}$

$0.62^{\mathrm{c}}$

Secundaria

$0.70^{\mathrm{c}}$

$0.50^{\mathrm{c}}$

Preparatoria

$0.58^{\mathrm{c}}$

$0.32^{\mathrm{c}}$

Profesional

$0.58^{\mathrm{c}}$

$0.34^{\mathrm{c}}$

Cohorte de nacimiento

Cohorte (1950-1959) (ref.)

Cohorte (1960-1970)

Cohorte (1971-1979)

Edad

6 a 10 (ref.)

11 a 15

16 a 20

21 a 29

Estudios hasta secundaria particular o pública

Pública (ref.)

Particular

Número de observaciones ${ }^{\mathrm{a}} \mathrm{p}<0.1,{ }^{\mathrm{b}} \mathrm{p}<0.05,{ }^{\mathrm{c}} \mathrm{p}<0.01$

$\begin{array}{lllllll}12012 & 11740 & 12012 & 12012 & 12012 & 12012 & 11740\end{array}$

Fuente: elaboración propia con base en datos de la Encuesta sobre Desigualdad y Movilidad Social en la Zona Metropolitana del Valle de México 2009. 
Con respecto a la situación migratoria, el modelo no ajustado muestra que es más probable salir de la escuela a cualquier edad para los migrantes de primera generación, particularmente los rurales. Los momios de salir de la escuela en cualquier edad para los migrantes de primera generación urbano y rural son 27 y 37 por ciento mayores que los de los nativos, respectivamente. El modelo ajustado muestra que al controlar por educación y ocupación del padre, la cohorte, la edad y la situación migratoria, los momios de salir de la escuela a cualquier edad para los migrantes de primera generación rural son 45 por ciento mayores que los de los nativos y sólo 17 por ciento menores en el caso de los migrantes de segunda generación respecto a los nativos. Es posible que lo anterior se deba a que estos últimos heredaron de sus padres el impulso emprendedor, además de que no tienen las condiciones desventajosas de origen que sus padres tuvieron, aunado al acceso al sistema educativo en la Ciudad de México. No obstante cabe resaltar que en el caso de los migrantes de primera generación rural el efecto se incrementa en comparación con los urbanos de primera generación cuyo coeficiente de hecho se vuelve no significativo, lo cual sugiere que ser migrante de primera generación rural implica un mayor riesgo de abandonar los estudios, debido principalmente a sus diferencias de origen - desventajas presentes antes de migrar-.

La ocupación del padre o sostén económico reporta coeficientes significativos como se esperaba: los momios de salir de la escuela a cualquier edad son cerca de 20 por ciento mayores para los hijos de padres que tuvieron ocupaciones comerciales que para los hijos de padres que tuvieron ocupaciones no manuales altas e intermedias; de manera similar, los momios son 48 por ciento mayores para los hijos cuyos padres tuvieron una ocupación manual baja que para los hijos de padres que tuvieron ocupaciones no manuales altas e intermedias. El modelo ajustado, en cambio muestra que el efecto sólo es significativo para los hijos de padres con ocupaciones manuales bajas frente a los hijos de padres que tuvieron ocupaciones no manuales altas e intermedias es decir se hace manifiesta la desigualdad entre estos dos grupos. Respecto a la escolaridad del padre o sostén económico, se observa un efecto significativo. El modelo no ajustado muestra que es menos probable salir de la escuela a mayor nivel de educación del padre, algo similar sucede con los momios del modelo ajustado. Lo anterior corrobora que la educación del padre tiene gran relevancia en la explicación de las desigualdades educativas entre los individuos en general y entre los migrantes y nativos en particular. 
Con respecto a las cohortes, el modelo no ajustado muestra que es menos probable salir de la escuela a cualquier edad para la cohorte más reciente, lo anterior posiblemente asociado al proceso de universalización en el acceso a la educación pública en México. El modelo ajustado no reportó efectos significativos en la edad de salida de la escuela por cohorte, lo que sugeriría que las otras variables absorben el efecto.

En el caso de las mujeres (Tabla 4) los momios de salir de la escuela son cerca de diez por ciento mayores para las migrantes de segunda generación respecto a las nativas, situación que no se evidenció en el caso de los hombres. Por otro lado, los momios de salir de la escuela son 41 y 50 por ciento mayores para las migrantes de primera generación urbanas y rurales respectivamente, que para las nativas. El modelo ajustado, muestra que al controlar por educación y ocupación del padre, la cohorte, la edad y la situación migratoria, los momios de salir de la escuela a cualquier edad para las migrantes de primera generación rural sigue siendo mayor que el de las nativas (1.38), de igual forma las migrantes de primera generación urbana presentan momios de salir de la escuela (1.41) mayores que el de las nativas.

Respecto a las migrantes de segunda generación el coeficiente se torna no estadísticamente significativo, lo que sugeriría que el efecto es absorbido por las otras variables. La ocupación del padre o sostén económico reporta algunas variantes respeto a lo evidenciado por los hombres, de entrada aunque el modelo sin ajustar muestra que es menos probable salir de la escuela a mejor estatus ocupacional del padre, el efecto sólo es significativo para las hijas de padres que tuvieron una ocupación comercial o manual frente a las hijas de padres que tuvieron ocupaciones no manuales altas e intermedias. El modelo ajustado, en cambio muestra que el efecto sólo es significativo para las hijas de padres con ocupaciones manuales bajas frente a las hijas de padres que tuvieron ocupaciones no manuales altas e intermedias, similar a lo evidenciado por los varones.

En el caso de la escolaridad del padre los coeficientes reportados son significativos, parecido a lo evidenciado entre los varones. El modelo no ajustado indica que es menos probable salir de la escuela a mayor nivel de educación del padre, lo que queda demostrado de igual forma en el modelo ajustado. Lo anterior apunta que uno de los determinantes principales en el logro educativo de los migrantes es la educación del padre y en menor medida su ocupación. 
Tabla 4: Modelo de tiempo discreto para la primera salida de la escuela para las mujeres. Razones de momios derivadas de los modelos logísticos binomiales (Ajuste de los modelos logísticos de tiempo discreto hasta los 29 años de edad)

\begin{tabular}{ccccccccc}
\hline & & & & & & & Modelo \\
ajustado
\end{tabular}

Generaciones de inmigrantes

Nativa (ref.)

2a. Generación

$1.09^{\mathrm{c}}$

1a. Generación urbana

1a. Generación rural

Ocupación del padre o sostén económico

No manuales altos e intermedios (ref.)

No manuales bajos

Comercio

Manual alto

Manual bajo

$1.49^{\mathrm{c}}$

Escolaridad del padre o sostén económico

Ninguna (ref.)

Primaria incompleta

$\begin{array}{ll}0.78^{\mathrm{c}} & 0.63^{\mathrm{c}} \\ 0.73^{\mathrm{c}} & 0.64^{\mathrm{c}} \\ 0.67^{\mathrm{c}} & 0.51^{\mathrm{c}} \\ 0.57^{\mathrm{c}} & 0.42^{\mathrm{c}} \\ 0.52^{\mathrm{c}} & 0.35^{\mathrm{c}}\end{array}$

Primaria completa

Secundaria

Preparatoria

Cohorte de nacimiento

Cohorte (1950-1959) (ref.)

Cohorte (1960-1970)

$\begin{array}{ll}0.83^{\mathrm{c}} & 0.79^{\mathrm{b}} \\ 0.78^{\mathrm{c}} & 0.74^{\mathrm{c}}\end{array}$

Cohorte (1971-1979)

Edad

6 a 10 (ref.)

11 a 15

16 a 20

$19.65^{\mathrm{c}}$

21 a 29

$29.05^{\mathrm{c}}$

Estudios hasta secundaria particular o pública

Pública (ref.)

Particular

Número de observaciones $\begin{array}{llllllll}10504 & 10281 & 10497 & 10504 & 10504 & 10504 & 10281\end{array}$ ${ }^{\mathrm{a}} \mathrm{p}<0.1,{ }^{\mathrm{b}} \mathrm{p}<0.05,{ }^{\mathrm{c}} \mathrm{p}<0.01$

Fuente: elaboración propia con base en datos de la Encuesta sobre Desigualdad y Movilidad Social en la Zona Metropolitana del Valle de México 2009. 
El efecto atribuido a las cohortes de nacimiento, muestra para el caso del modelo no ajustado que es menos probable salir de la escuela a cualquier edad para las mujeres de la cohorte más reciente, muy parecida a lo evidenciado por los hombres. Si alguna diferencia existe, se da en la cohorte intermedia donde las mujeres presentan momios 17 por ciento menores de salir de la escuela a cualquier edad. En cambio los hombres para esa misma cohorte el coeficiente era no significativo. El modelo ajustado corroboró lo anterior.

Ahora bien, para observar los términos de interacción entre la situación migratoria y las categorías de edad para los varones, es necesario realizar cálculos adicionales que permitan no sólo comparar la probabilidad de salida de la escuela según la situación migratoria en las diferentes edades, sino también contrastar la situación migratoria en cada grupo de edad, que es el objetivo central del siguiente apartado. Lo anterior con el objeto de evidenciar si la situación migratoria tiene un efecto diferencial en la edad de salida de la escuela.

\section{Efectos de la Situación Migratoria por SeXo sobre la PROBAbi- LIDAD DE SALIR DE LA ESCUELA SEGÚN GRUPOS DE EDAD}

La Tabla 5 muestra los efectos de la situación migratoria sobre las probabilidades de salir de la escuela para los varones. Los resultados sugieren que el efecto de la situación migratoria depende de la edad. Las probabilidades de salir de la escuela antes de los 16 años son mucho mayores para los migrantes de primera generación rural (la razón de momios con respecto a los nativos es 9.56 en el tramo de edades 6-10 y 3.03 en el 11-14). Sin embargo, en edades posteriores los migrantes rurales que lograron permanecer en la escuela hasta los 15 años de edad ya no presentan diferencias con otros grupos, incluidos los nativos. Lo anterior sugiere que el desempeño diferente de los migrantes de primera generación rural, particularmente en lo educativo, es principalmente resultado de sus diferencias de origen (desventajas ya presentes cuando migraron), razón por la cual el efecto de ser migrante rural se manifiesta sólo antes de los 16 años. No hay duda, que dejar la escuela a edades tempranas es un elemento importante de desventaja para los migrantes de primera generación, (particularmente los rurales) en comparación con los nativos, lo que a su vez tendrá un impacto sobre la calidad de la inserción laboral a causa de que los bajos niveles de escolaridad están asociados con una mayor precariedad de los empleos (Oliveira, 2006; Oliveira y Mora, 2008). 
Tabla 5: Efectos de la adscripción migratoria sobre la probabilidad de salida de la escuela. Razones de momios calculadas a partir de la interacción entre las generaciones de migrantes y la edad (hombres)

\begin{tabular}{lcccc}
\hline Variable & $\begin{array}{c}\text { a } 10 \text { años } \\
\text { Odds Ratio }\end{array}$ & Odds Ratio & Odds Ratio & Odds Ratio \\
\hline
\end{tabular}

Generaciones de migrantes

Nativo (ref.)

\begin{tabular}{lrrrrrr} 
2a. Generación & 1.81 & & 1.21 & 0.93 & 0.86 \\
1a. Generación urbana & 3.98 & $*$ & 2.66 & $* * *$ & 1.07 & 1.32 \\
1a. Generación rural & 9.56 & $* * *$ & 3.03 & $* * *$ & 1.12 & 1.13 \\
Número de observaciones & 4684 & & 4121 & & 2142 & 1065 \\
\hline
\end{tabular}

$* \mathrm{p}<0.1 * * \mathrm{p}<0.05 * * * \mathrm{p}<0.01$

Fuente: elaboración propia con base en datos de la Encuesta sobre Desigualdad y Movilidad Social en la Zona Metropolitana del Valle de México 2009.

En el caso de las mujeres (Tabla 6), los resultados son parecidos, aunque con diferencias de mayor magnitud entre migrantes y nativas. Entre seis y diez años de edad, los momios de salir de la escuela son 24 veces mayores para las migrantes de primera generación urbana que para las nativas y casi 28 veces mayores entre las rurales de primera generación respecto a las nativas. En el siguiente grupo de edad (de los 11 a los 15 años) aunque las razones de momios de salir de la escuela disminuyen, aún sigue representando una desventaja para las socializadas fuera de la Ciudad de México, particularmente las rurales. A partir de los 16 años y hasta los 29 años, la edad de la salida de la escuela no está determinada por ser migrante de primera generación rural y desde los 21 años hasta los 29 años por haber socializado fuera de la ZMVM. Llama la atención que las migrantes de segunda generación presenten coeficientes significativos para todos los grupos de edad y que entre seis y 20 años muestren mayores posibilidades de salir de la escuela que las nativas particularmente a las edades más tempranas y que sólo hasta el grupo de 21 a 29 años sus posibilidades de salir de la escuela sean casi un tercio menor. Lo anterior es interesante porque sugiere que existen diferencias significativas en los patrones de inserción (Santiago, 2012 y 215) de los varones y mujeres migrantes, en el sentido de que las mujeres no lograron una adaptación plena a la segunda generación contrario a lo evidenciado por los hombres. ${ }^{19}$

Pero ¿Por qué hay déficit en la segunda generación de las mujeres y no en la de los varones? Una posible respuesta, dada por la literatura, es que el patrón reportado en el caso de las mujeres, es indicativo de las formas en que opera la división sexual del trabajo de los hogares. El retiro de

${ }^{19}$ Es posible que tengan hijos más tempranamente, es decir un modelo transicional de familia. 
las mujeres del sistema escolar puede estar acompañado de mayores responsabilidades en la realización de los quehaceres domésticos y cuidado de los hermanos y adultos mayores al interior de sus familias. Resultados similares son reportados por otros autores para el conjunto de la población juvenil (Horbath, 2004; Gandini y Castro, 2006). No obstante, los resultados de este trabajo coinciden con lo evidenciado por Oliveira y Mora, quienes argumentan que este es un comportamiento propio de las mujeres de escasos recursos. Tal parece que las pautas de división sexual del trabajo presentan una mayor persistencia en los contextos sociales más desfavorecidos en términos socioeconómicos (Oliveira y Mora, 2008: 127). En este mismo sentido Mier y Terán (2004), muestra que las jóvenes en comunidades rurales marginadas salen de la escuela más temprano que los varones pero inician su vida laboral en menor proporción que ellos a todas las edades.

Tabla 6: Efectos de la adscripción migratoria sobre la probabilidad de salida de la escuela.

Razones de momios calculadas a partir de la interacción entre las generaciones de migrantes y la edad (mujeres)

\begin{tabular}{|c|c|c|c|c|c|}
\hline \multirow{2}{*}{$\begin{array}{l}\text { Variable } \\
\text { Generaciones de migrantes }\end{array}$} & $\begin{array}{l}6 \text { a } 10 \text { años } \\
\text { Odds Ratio }\end{array}$ & $\begin{array}{c}11 \text { a } 15 \text { años } \\
\text { Odds Ratio }\end{array}$ & $\begin{array}{c}16 \text { a } 20 \text { años } \\
\text { Odds Ratio }\end{array}$ & \multicolumn{2}{|c|}{$\begin{array}{r}21 \text { a } 29 \text { años } \\
\text { Odds Ratio }\end{array}$} \\
\hline & & & & & \\
\hline \multicolumn{6}{|l|}{ Nativa (ref.) } \\
\hline 2a. Generación & $4.47 * *$ & $1.36 * * *$ & $1.30 *$ & 0.72 & $* * *$ \\
\hline 1a. Generación urbana & $25.08 * * *$ & $1.92 * * *$ & $1.75 * *$ & 1.83 & \\
\hline 1a. Generación rural & $28.59 * * *$ & $3.11 * * *$ & 1.11 & 0.66 & \\
\hline Número de observaciones & 4483 & 3749 & 1673 & 599 & \\
\hline
\end{tabular}

\section{Determinantes del logro educativo}

Es pertinente recordar que este trabajo tiene por interés valorar la influencia de la situación migratoria en dos aspectos centrales de las trayectorias educativas: la edad a la salida de la escuela y el logro educativo. Hasta ahora sólo se han presentado las particularidades a la salida del sistema educativo, captando la importancia de la situación migratoria, variables individuales y contextuales, además de su interacción con la edad en la deserción en las carreras educativas de los migrantes y nativos por sexo. Para complementar lo anterior analizaremos en esta sección la influencia de la situación migratoria en el logro educativo. Para esto se indagará sobre 
si las oportunidades educativas están determinadas por la situación migratoria aún después de tener en cuenta el estatus socioeconómico familiar, el sexo y la cohorte.

Antes de comenzar con el estudio de los determinantes del logro educativo, es oportuno señalar que se decidió iniciar este apartado de manera previa con un análisis por cohorte de nacimiento, de modo que podamos trazar, de manera descriptiva, las diferencias generadas en el logro educativo de los sujetos asociadas a cambios en el tiempo, producto de los procesos de universalización en el acceso a la educación pública a partir de los años 1970, además de las transformaciones relacionadas con el desarrollo urbano del país. En ese sentido, en el presente apartado se procura estudiar las transformaciones estructurales en intervalos de tiempo delimitados y su impacto sobre las oportunidades de logro educativo de cada una de las cohortes que se distinguen para efectos del análisis.

\section{CAMbIOS POR COHORTE Y SEXo EN EL LOGRO EDUCATIVO de los migrantes en la Ciudad de México}

La Tabla 7 presenta las razones de momios de modelos de regresión logística ordenados que miden el efecto de las distintas generaciones de migrantes varones sobre el logro educativo para tres diferentes cohortes. Cabe recordar que la variable dependiente es el nivel de escolaridad alcanzado por el individuo, clasificado en seis categorías (ninguna, primaria incompleta, primaria completa, secundaria completa e incompleta, preparatoria completa e incompleta y profesional), tal como se presenta en el anexo.

Los resultados del modelo no ajustado sobre logro educativo de los migrantes no muestra evidencia estadística suficiente entre los migrantes de segunda generación en todas las cohortes de nacimiento, lo que sugiere que las otras categorías de migrantes absorben el efecto. En contraste, los migrantes de primera generación rural desde la cohorte más antigua (19501959) mostraron un déficit en términos de logro educativo, los momios de 0.29 lo confirman, sugiriendo una mayor probabilidad de ser empujados al fondo de la estructura social debido a la asociación con los bajos niveles educativos. En la cohorte intermedia la situación no mejora, de hecho parece que se mantiene el déficit hasta la cohorte más reciente. Llaman la atención los migrantes de primera generación urbana, que en la cohorte (1950-1959) mostraban déficit en el logro educativo, pero a partir de la cohorte intermedia los momios se vuelven no significativos. 
Tabla 7: Efectos no ajustados del origen migratorio sobre el logro educativo. Razones de momios del modelo de regresión logística ordenado (Hombres)

\begin{tabular}{llll}
\hline Máximo nivel educativo & $1950-1959$ & $1960-1970$ & $1971-1979$ \\
& Odds Ratio & Odds Ratio & Odds Ratio \\
\hline
\end{tabular}

Generaciones de migrantes

Nativo (ref.)

2a. Generación

0.77

1a. Generación urbana

$0.45 * *$

0.70

0.43

1a. Generación rural

$0.29 * * *$

$0.16 * * *$

$0.29 *$

Número de observaciones

$* \mathrm{p}<0.1 * * \mathrm{p}<0.05^{* * *} \mathrm{p}<0.01$

256

349

339

Fuente: elaboración propia con base en datos de la Encuesta sobre Desigualdad y Movilidad

Social en la Zona Metropolitana del Valle de México 2009.

En el caso de las mujeres, la historia es completamente distinta. De hecho la Tabla 8 muestra que desde la cohorte más antigua (1950-1959) las migrantes de segunda generación mostraron déficit de logro educativo, los momios de 0.38 de las migrantes de segunda generación confirman que desde entonces había déficit de logro educativo entre ellas. Resalta que las migrantes de segunda generación presenten un coeficiente no significativo en la cohorte intermedia, no obstante el déficit de logro educativo se mantiene en la última cohorte, aunque con una leve disminución.

Tabla 8: Efectos no ajustados del origen migratorio sobre el logro educativo. Razones de momios del modelo de regresión logística ordenado (mujeres)

\begin{tabular}{lccc}
\hline Máximo nivel educativo & $\begin{array}{c}1950-1959 \\
\text { Odds Ratio }\end{array}$ & $\begin{array}{c}1960-1970 \\
\text { Odds Ratio }\end{array}$ & $\begin{array}{c}1971-1979 \\
\text { Odds Ratio }\end{array}$ \\
\hline $\begin{array}{l}\text { Generaciones de migrantes } \\
\text { Nativa (ref.) }\end{array}$ & & & \\
2a. Generación & $0.38 * * *$ & 1.06 & $0.57 * *$ \\
1a. Generación urbana & $0.26 * *$ & $0.25 * * *$ & $0.07 * * *$ \\
1a. Generación rural & $0.06 * * *$ & $0.17 * * *$ & $0.23 * *$ \\
Número de observaciones & 248 & 344 & 318 \\
\hline$*$ p & & &
\end{tabular}

$* \mathrm{p}<0.1^{* *} \mathrm{p}<0.05^{* * *} \mathrm{p}<0.01$
Fuente: elaboración propia con base en datos de la Encuesta sobre Desigualdad y Movilidad Social en la Zona Metropolitana del Valle de México 2009. 
Por su parte las migrantes de primera generación urbana, el análisis entre cohortes apunta hacia un fuerte déficit en el logro educativo y empeora en la cohorte más reciente. En contraste, los resultados entre las cohortes de las migrantes de primera generación rural, muestran que los momios de alcanzar un mayor nivel educativo respecto a las nativas indican una reducción en términos del déficit de logro educativo. No obstante, el panorama no es del todo halagador, la razón de momios de 0.23 entre las migrantes de primera generación rural de la cohorte más reciente, al ser significativa sugiere una menor probabilidad de alcanzar un mayor nivel educativo en relación con las nativas, señalando que haber socializado fuera de la Ciudad de México, trae consigo algunas desventajas asociadas con los orígenes sociales y bajos niveles de escolaridad.

De aquí se desprende que en el caso de los varones migrantes de primera generación rural es persistente su condición desventajosa con respecto a los nativos para lograr un mayor nivel educativo, sobre todo en la cohorte intermedia, lo anterior llama la atención sobre todo en un contexto de mejoramiento, como se ha venido mencionando, en la cobertura educativa de las últimas décadas. En el caso de las mujeres, la tendencia es hacia la reducción del efecto negativo en términos de logro educativo, particularmente entre las migrantes rurales, no obstante su desventaja es tal al inicio que aún en la cohorte más reciente muestran una brecha muy amplia en logro educativo con respecto a las nativas.

\section{DETERMinANTES DEL LOGRO EDUCATIVO DE LOS MigRANTES}

Hasta ahora se ha considerado en el análisis únicamente la asociación entre el logro educativo y la situación migratoria por cohorte y sexo en forma individual. No obstante, dado que son múltiples los factores que intervienen en el logro educativo de los migrantes, es necesario pasar a una explicación multidimensional que permita conocer el efecto de cada variable "controlando" por las otras. Para ello se ajustaron seis modelos donde la variable dependiente continúa siendo el nivel educativo. Como variables independientes se incluye la condición migratoria, la ocupación y escolaridad del padre, así como la cohorte de nacimiento (Tabla 9 y Tabla 10).

Los resultados para los varones se presentan en la Tabla 9. Los coeficientes de los modelos no ajustados por situación migratoria sintetizan los efectos ya observados en el Tabla 7. Los momios de alcanzar un nivel educativo más alto son menores para los migrantes de primera generación urbana y rural que para los nativos. En cambio en el modelo ajustado al controlar por ocupación y educación del padre, así como por la cohorte de 
nacimiento, los momios sugieren una mayor probabilidad, entre los migrantes de segunda generación, de alcanzar un nivel educativo más alto que los nativos. El efecto negativo de ser migrante de primera generación urbana desaparece en el modelo ajustado, en contraste los migrante de primera generación rural mantienen el efecto negativo aunque con una leve reducción en los momios, lo que sugiere que el hecho de ser migrante si "explica" parte del por qué algunas personas alcanzan un nivel educativo más alto que otras. Es probable que esto también se deba a ciertos factores asociados a características que ya traen consigo cuando llegan a la Ciudad de México y que hace que los migrantes rurales tengan una menor propensión a alcanzar niveles educativos más altos y por tanto a ubicarse en las ocupaciones de menor jerarquía (Santiago, 2015).

El estatus ocupacional del padre muestra también un efecto substancial. Una mejor ocupación del padre implica que los momios de alcanzar un nivel educativo más alto sean más grandes y viceversa. En el modelo ajustado, el efecto de las ocupaciones de los padres - el comercio y los manuales altos - sobre el logro educativo de los hijos desaparece (los coeficientes se vuelven no significativos). No obstante la hipótesis de que una mejor ocupación del padre contribuye a un mejor nivel educativo de los hijos se sostiene, los momios de 0.50 y 0.56 entre los hijos de padres con ocupaciones manuales bajas y no manuales bajas, respectivamente, así lo confirman.

La educación del padre por su parte muestra más claramente un efecto sustancial tanto en el modelo no ajustado como ajustado. Un mayor nivel educativo del padre hace más probable alcanzar un nivel educativo más alto, en especial para los hijos de padres con educación superior. Por ejemplo, los momios de alcanzar un nivel educativo más alto son (1.46) veces más grandes para individuos cuyos padres alcanzaron educación primaria incompleta que para individuos cuyos padres no alcanzaron ningún nivel educativo. El efecto sobre los momios se incrementa a medida que el nivel educativo del padre es mayor, pero como ya se había señalado, la educación superior del padre marca una gran distancia frente los momios de alcanzar un nivel educativo más alto, dichos momios son (13.84) veces más grandes para los hijos de padres que alcanzaron educación superior que para los hijos de padres que no alcanzaron ningún nivel educativo. 


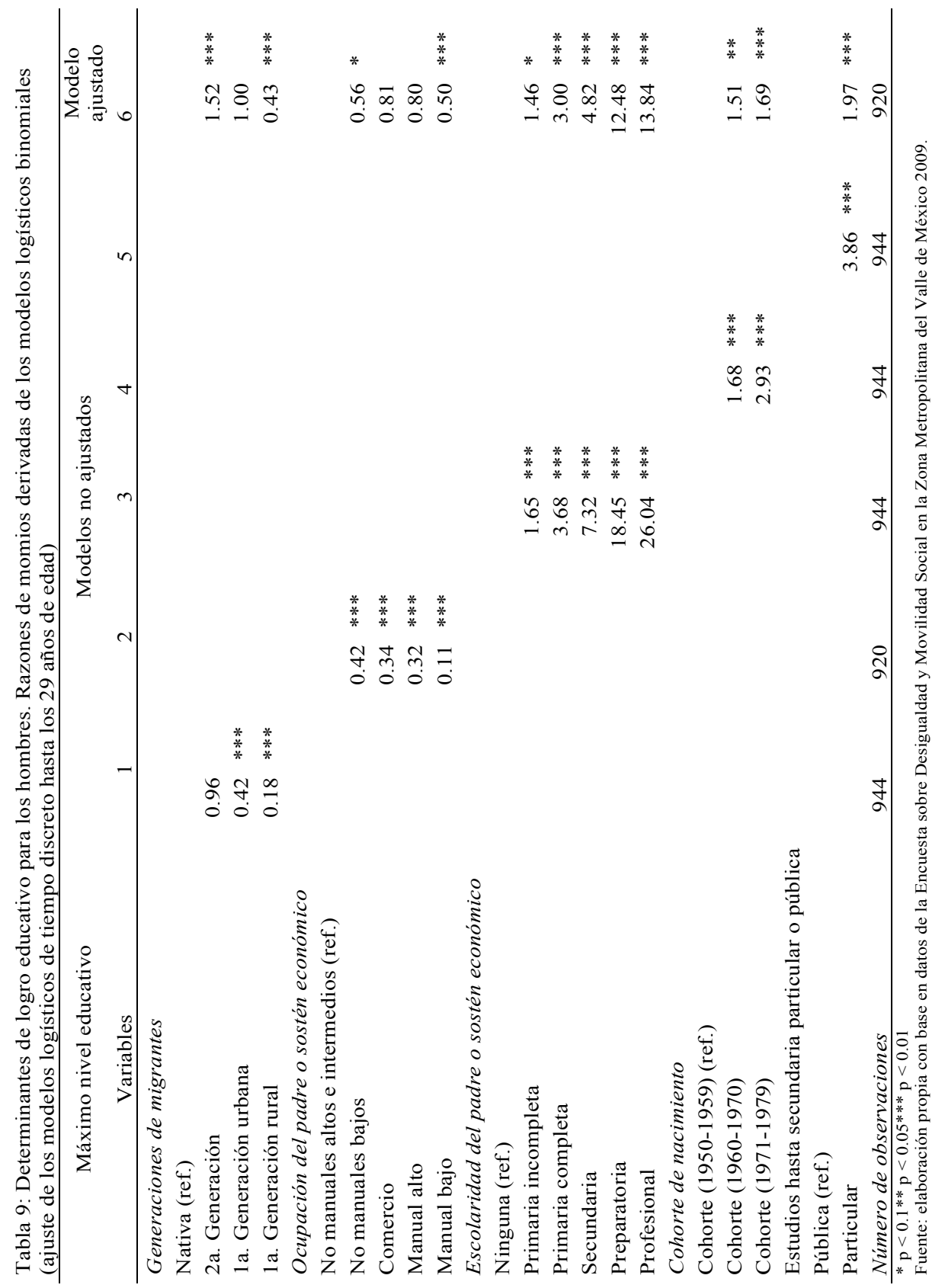


Determinantes del logro educativo de los migrantes en la Ciudadde Mexico / J. SANTIAGO-HERNÁNDEZ

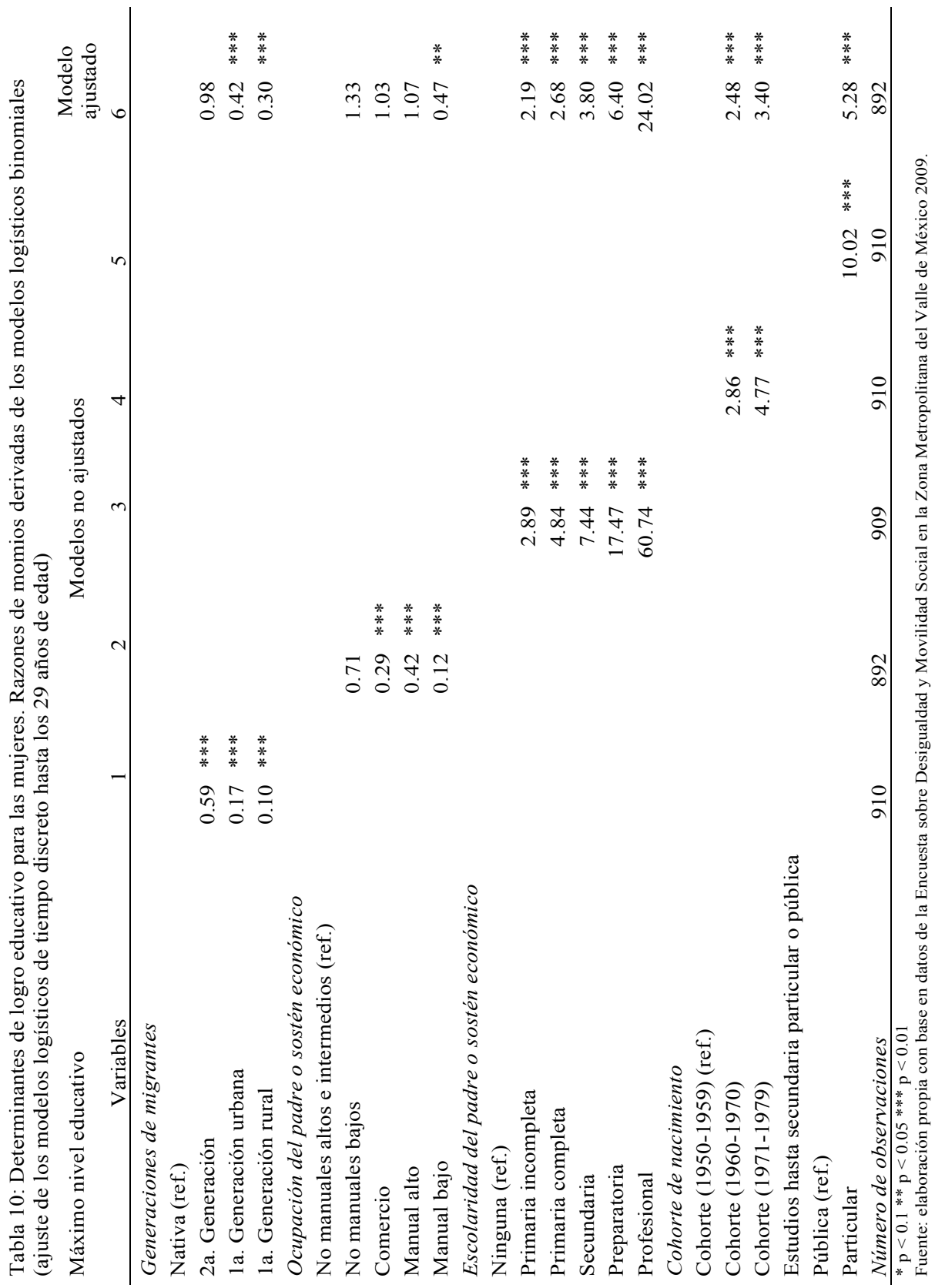


En el análisis de los efectos de la cohorte de nacimiento, el modelo no ajustado confirma el progreso en los niveles educativos en la Ciudad de México desde la década de los setenta. Los momios de alcanzar un nivel educativo son 1.68 veces más grandes para los de la segunda cohorte que para los de la primera cohorte. El efecto de las políticas de universalización de la educación en nuestro país de los años setenta se ve reflejado de manera más clara en el incremento de los momios de alcanzar un nivel educativo más alto de 2.93 para la cohorte (1971-1979), en relación a la primera cohorte. El modelo ajustado corrobora esta reducción de los efectos en los niveles educativos. Al respecto cabe recordar las cifras citadas en las estadísticas demográficas, las cuales han documentado un ligero incremento en el nivel promedio de escolaridad de hombres y mujeres mayores de 15 años de edad en el país, el cual pasó de 2.6 años de escolaridad en promedio en 1960 a 5.5 años en 1980, 6.6 años en 1990 y 7.4 años en 1997 (INEGI, 2000).

Respecto a las mujeres según su situación migratoria, el modelo no ajustado confirma las diferencias en las oportunidades educativas (Cuadro 10). En todos los casos las migrantes de primera y segunda generación presentan un déficit en el logro educativo. El modelo ajustado, una vez que se controla por los orígenes sociales y la cohorte de nacimiento, los momios de alcanzar un mayor nivel educativo se vuelven no significativos en el caso de las migrantes de segunda generación indicando que no hay evidencia estadística suficiente (coeficientes no significativos) para hacer alguna inferencia, lo que sugiere que las otras variables absorben el efecto negativo. No obstante, no es lo mismo ser una migrante urbana que una rural, pues son estas últimas quienes presentan las mayores desventajas educativas (los momios de 0.42 y 0.30 de las migrantes de primera generación urbana y rural, así lo sugieren), que más tarde se transforman en inserciones ocupacionales deficitarias (Santiago, 2015).

La ocupación del padre muestra también un efecto sustancial, aunque las hijas de padres con ocupaciones no manuales bajos no reportan un efecto significativo sobre los momios de alcanzar un nivel educativo más alto en relación a las hijas de padres con ocupaciones no manuales altas. No obstante, al igual que con los varones, se mantiene la tendencia a mayores logros educativos entre quienes provienen de familias cuyo padre o jefe económico tenía una ocupación de mayor jerarquía. El modelo ajustado, muestra que las hijas de padres con ocupaciones manuales bajas reportan un déficit en términos de logro educativo en relación con las hijas de los padres con ocupaciones no manuales altas, el resto de las categorías se 
tornan no estadísticamente significativas, lo que sugiere que el efecto se manifiesta por las otras variables.

Por su parte, la educación del padre tiene efectos muy poderosos sobre el logro educativo, y conserva su importancia incluso luego de controlar por las otras variables. Tanto en el modelo ajustado como el no ajustado se observa que un mayor nivel educativo del padre hace más probable alcanzar un nivel educativo más alto, sobre todo entre las hijas de padres con educación superior. Lo anterior ratifica, como se ha venido diciendo, la importancia de los orígenes sociales medidos por medio de la educación del padre o sostén económico.

En el análisis de los efectos de la cohorte de nacimiento, obsérvese que los momios de alcanzar un nivel educativo más alto son 2.86 veces mayores para la segunda cohorte que para la primera cohorte, y 4.77 veces mayores para la cohorte más reciente que para la primera. Sin duda, como se ha mencionado, asociado a los avances importantes en materia educativa en nuestro país desde la década de los setenta, sobre todo para la población femenina.

En suma, los resultados sugieren que los mecanismos que generan y reproducen la desigualdad en las oportunidades educativas según la situación migratoria en la Ciudad de México, particularmente en lo educativo, son principalmente resultado de sus diferencias de origen (desventajas ya existentes cuando migraron), y sólo de manera secundaria resultado de las desventajas que enfrentan ya en la Ciudad de México (Santiago, 2015).

\section{CONSIDERACIONES FINALES}

Este trabajo tuvo por objetivo analizar la influencia de la situación migratoria en dos aspectos centrales de las trayectorias educativas: la edad a la salida de la escuela y el logro educativo. Interesaba saber si los migrantes presentaban desventajas educativas con respecto a los nativos, si estas estaban asociadas a las desventajas en el acceso a la educación en sus comunidades de origen antes de migrar, o bien a que sus trayectorias educativas se truncaran más tempranamente una vez que llegaron a la Ciudad de México. En esencia, de existir tales diferencias interesaba ver si éstas se debían directamente a la situación migratoria actual, o bien a otras características que se le asocian, como son los orígenes sociales (medido por la educación y ocupación del padre), y otras variables sociodemográficas individuales (como el sexo) y contextuales (como la cohorte de nacimiento). Sobre la base de esto y retomando los resultados de este trabajo, a continuación se apuntan las siguientes reflexiones finales. 
En primer lugar, la población inmigrante de primera generación rural presenta el calendario más joven de salida de la escuela. Esto implica que los residentes de la Ciudad de México que fueron socializados en áreas rurales estuvieron por menos tiempo en la escuela, tuvieron menores logros educativos, enfrentaron la desafiliación educativa a edades más tempranas, y se vieron en situación de experimentar otras transiciones que típicamente siguen a la salida de la escuela de manera más precoz que quienes tenían otras características migratorias. Cuando consideramos a las mujeres, las migrantes de primera generación rural son las que mostraron notoriamente mayores desventajas en sus carreras educativas en relación con sus congéneres migrantes de segunda generación y nativas. Estas diferencias podrían ser más significativas si consideramos además los efectos sobre la edad de salida de la escuela que representan la escolaridad del padre, sugiriendo que las migrantes de primera generación rural enfrentan mayores limitaciones en el curso de vida que les impide desarrollar carreras educativas exitosas.

Para explicar la brecha entre migrantes y nativos, los resultados presentados en este trabajo confirmaron que estas diferencias se debían a características que ya traían consigo cuando migraron, de hecho los resultados de la Tabla 6 y la Tabla 7 apuntaron a que la brecha entre migrantes y nativos se debía (particularmente en el caso de las diferencias educativas y las desventajas de los migrantes rurales) a los diferenciales ya existentes cuando los migrantes llegaron a la Ciudad de México.

En tercer lugar, la escolaridad del padre confirma la gran importancia en la explicación de las desigualdades educativas entre individuos. Una mayor escolaridad del padre es muy probable que este asociada a un mayor estatus socioeconómico familiar, lo que constituye no sólo mayores recursos para brindar a los hijos continuidad y calidad en sus carreras educativas, sino también la transmisión intergeneracional de las habilidades y percepciones positivas acerca de la educación.

También la situación migratoria ejerce una gran influencia en las oportunidades educativas. Las inequidades entre nativos y migrantes de primera y segunda generación podrían sustentarse en los mecanismos institucionales que operan en las zonas rurales y urbanas en relación con el trabajo infantil y la asistencia al sistema educativo, además del mismo fenómeno de la migración. Es muy probable que muchos de los migrantes hayan realizado sus primeros años de escolaridad en las áreas rurales, en las cuales hay un mayor costo de oportunidad de desarrollar actividades agrícolas cómo trabajadores familiares sin remuneración o peones a temprana edad, 
interrumpiendo sus carreras educativas. Esto también afecta probablemente a las personas que migraron a temprana edad e iniciaron sus carreras educativas en la Ciudad de México, en la mayoría de los casos, la posición de desventaja social en la que llegan sus padres o familiares, es posible que afecté el abandono del sistema educativo empujándolos a emplearse en actividades manuales de baja calificación, situación que podría extenderse para los migrantes de segunda generación y nativos de clases bajas en la ciudad.

Varios factores podrían estar influenciando la conducta por cohortes. En primer lugar, y cómo en el resto del país, el efecto de la industrialización, urbanización a partir de los años cincuenta y el incremento en la oferta en los servicios educativos desde la década de los setenta como se sugirió a lo largo del trabajo, posibilitaron una mayor permanencia en el sistema escolar y por ende un incremento en los niveles educativos a través de las distintas cohortes; no obstante, como se ha evidenciado, no han sido suficientes para revertir las desigualdades crecientes en nuestro país particularmente entre las mujeres migrantes de origen rural, cuyas políticas de expansión en la educación en el país siguen dejándolas marginadas, lo cual obliga a pensar en otra estrategia, que contribuya de manera efectiva a reducir tales inequidades, no sólo en términos de años de escolaridad, sino además en la calidad de la misma que permita realmente un incremento en su grado de competitividad en términos de oportunidades ocupacionales, dado el aumento creciente en los requerimientos formales para ingresar al mercado de trabajo de la Ciudad de México.

Por último, el presente trabajo dejó entrever la necesidad de realizar mayores esfuerzos para vislumbrar los mecanismos que fomentan la desigualdad de oportunidades educativas entre nativos e inmigrantes tanto en otras ciudades como en el ámbito nacional. En ese sentido, los efectos de la situación migratoria en el cambio estructural y la movilidad socio-ocupacional y el logro educativo deben ser valorados en futuras investigaciones, a la luz de metodologías más avanzadas, apoyados en marcos analíticos como el de los estudios de estratificación, logro educativo y ocupacional, que nos permitieron realizar aportaciones importantes y originales al tema de estudio. Pensamos que los resultados que se mostraron en esta investigación son interesantes y novedosos por sí mismos, en el sentido de que en los estudios que se revisaron en este trabajo evidenciaron que se conoce muy poco acerca de la migración femenina a la Ciudad de México y mucho menos sobre la distinción según situación migratoria a partir de las generaciones de migrantes, lo cual también constituye un avance teórico- 
metodológico sustancial para el análisis de los procesos intergeneracionales de incorporación social.

\section{Anexo}

A continuación se describen las variables utilizadas para el análisis; también se muestra las características, codificación y nombres de las variables:

\section{Las variables dependientes}

- Salida de la escuela (modelo logístico de tiempo discreto): Esta variable dependiente se refiere a si el individuo experimentó (1), o no experimentó (0), la salida de la escuela. Se trata de una variable que permite valorar la probabilidad de que una persona cambie de un estado a otro.

- Escolaridad ego (modelo logístico ordenado): ${ }^{20}$ Es una variable que mide capacidades, conocimientos, competencias y cualificaciones de los individuos. Será medido por los años de escolaridad alcanzado por el ego.

\section{Las variables independientes}

- Situación migratoria: ${ }^{21}$ Se codifica como 0 para los "Nativos", ${ }^{22} 1$ "Migrantes de segunda generación", ${ }^{23} 2$ "Migrantes de primera generación urbana" 24 y 3 "Migrantes de primera generación rural" (Véase Santiago, 2012). ${ }^{25}$

- Edad (variable sólo incluida para el análisis del modelo de tiempo discreto): Son los años persona en riesgo de experimentar la salida de

\footnotetext{
${ }^{20}$ Los efectos positivos del logro educativo en la estratificación y movilidad social han sido bien documentados en los estudios de estratificación y movilidad social e inversión en capital humano e ingresos (Blau y Duncan, 1967). La dotación de mejores credenciales educativas constituye una ventaja en el mercado de trabajo, en especial, en el acceso a las ocupaciones de mayor estatus en las cuales existe una mayor competencia. En ese sentido, el nivel educativo se incluye como una variable que mide capacidades, conocimientos, competencias y cualificaciones de los individuos. ${ }^{21}$ La manera convencional para diferenciar a una población como la que se pretende analizar en este trabajo, consiste en utilizar la distinción nativo-migrante, que es la que existe en casi todos los censos y en la mayor parte de las encuestas. De tal suerte que si una persona es entrevistada en un lugar distinto a su lugar de nacimiento, se le clasifica como migrante, y si nació en la comunidad se le clasifica como nativa. Pero esta distinción se hace sólo con base en el lugar de nacimiento por lo que esta diferenciación dista de ser ideal. Lo que interesa en este trabajo es presentar una diferenciación más detallada que tome en cuenta a su "comunidad de origen" aquella en la que el individuo paso la mayor parte del tiempo entre los 5 y los 15 años de edadcomo los estudios clásicos de Browning y Feindt 1969 y Muñoz et al. 1977. Pues haber nacido en determinada localidad tiene poca importancia sociológica comparada con la que tiene el haber pasado la mayor parte del periodo de "socialización" en ella.

${ }_{22}^{2}$ El padre nació en la Ciudad de México y ego también.

${ }^{23}$ El padre nació fuera de la Ciudad de México, pero ego nació y/o socializó en la Ciudad.

${ }^{24}$ Ego socializó y nació fuera de la Ciudad de México en una comunidad urbana.

${ }^{25}$ Ego socializó y nació fuera de la Ciudad de México en una comunidad rural.
} 
la escuela se incluyen en el modelo cómo una variable "dummy" de cuatro categorías: la primera categoría se define de los seis a diez años de edad (6-10); la segunda categoría de once a quince años (11-15); la tercera categoría de dieciséis a veinte años (16-20) y finalmente la última categoría de los veintiuno a los veintinueve años (21 a 29). Con lo anterior se asume que la probabilidad de ocurrencia del evento no varía al interior de cada categoría, pero si entre categorías.

- Sexo: ${ }^{26}$ La variable se codifica como 1 para los hombres y 0 para las mujeres.

- Cohorte de nacimiento: esta variable se codifica como 1 "1950-1959", 2 “1960-1970” у 3 “1971-1979”, con ella se busca controlar la influencia de los cambios socio-demográficos y socio-económicos de larga duración en el último tercio del siglo XX.

- Para medir la influencia de los orígenes sociales en el calendario de salida de la escuela y el logro educativo introducimos al modelo la escolaridad y la ocupación del padre: ${ }^{27}$

- Ocupación del padre o sostén económico: Esta variable se obtiene de clasificar la ocupación del padre o sostén económico a los 15 años de la persona entrevistada. Se codifica como 0 "No manuales alta calificación", 1 "No manual baja calificación", 2 "Comercio", 3 "Manual alta calificación" y 4 "Manual baja calificación".

- Escolaridad del padre o sostén económico: Es una variable que esta medida a partir de los año de escolaridad del padre o sostén económico a los 15 años de la persona entrevistada. Se trata de un elemento (al igual que la ocupación del padre) que permite valorar la importancia de los orígenes sociales en el proceso de logro de estatus ocupacional.

\footnotetext{
${ }^{26}$ La variable sexo es un principio articulador de factores demográficos (sexo biológico), culturales (roles de género establecidos) y sociales (cómo dichos roles se reafirman o transforman durante la experiencia migratoria). El género es un principio organizador básico que configura identidades, comportamientos y relaciones de poder que se construyen socialmente en relación con el sexo biológico (Paredes, 2009). Este principio subyace en los procesos migratorios, de modo que las relaciones de género pueden configurar el logro ocupacional.

${ }^{27}$ Con ello, se distinguen tres formas de transmisión intergeneracional de estatus socioeconómico: la primera se refiere a las desigualdades en las oportunidades de educación; la segunda enfatiza que las aspiraciones, características de personalidad y valores de los individuos son fuertemente afectados por las características de la familia y modelos culturales dominantes en la sociedad; por último, las habilidades intelectuales también podrían transmitirse intergeneracionalmente de padres a hijos.
} 


\section{REFERENCIAS BIBLIOGRÁFICAS}

ANUIES, 1996, Mercado laboral de profesionistas en México, México, Asociación Nacional de Universidades e Instituciones de Educación Superior.

Balán, J., Browning, H. L. y Jelín, E., 1977, El hombre en una sociedad en desarrollo. Movilidad geográfica y social en Monterrey, México, Fondo de Cultura Económica.

Balán, J., H. L. Browning, y Jelín, E., 1973, Migración, estructura ocupacional y movilidad social (el caso de Monterrey), México, UNAM.

Balán, J., 1969, "Migrant-native socio-economic differences in Latin American cities: a structural analysis", in Latin America Research Review, vol. 4, núm. 1, pp. 3-29.

Billari, F., y Philipov, D., 2004, "Education and the transition to motherhood: A comparative analysis of Western Europe", in European Demographic Research Papers.

Blanco, Emilio; Solís, Patricio y Robles, Hector, 2014, Caminos desiguales: trayectorias educativas y laborales de los jóvenes en la Ciudad de México. México: INEE-El Colegio de México.

Blau, P. y Duncan, O. D., 1967, The American occupational structure, New York, Wiley.

Browning Harley y Corona, Rodolfo, 1995, "La migración inesperada de los chilangos", en Demos. Carta demográfica sobre México, pp.16-17.

Camposortega-Cruz, Sergio, 1992, “Evolución y tendencias demográficas de la Zona Metropolitana de la Ciudad de México" en Conapo, La zona metropolitana de la Ciudad de México. Problemas actuales y perspectivas democráticas y urbanas, México, pp. 3-15.

CONAPO, 2000, "Migración interna en México", en La población de México en el nuevo siglo, México, Consejo Nacional de Población.

Contreras-Suárez, Enrique, 1978, Estratificación y movilidad social en la Ciudad de México, México, UNAM-Instituto de Investigaciones Sociales.

Contreras-Suárez, Enrique, 1972, “Migración interna y oportunidades de empleo en la Ciudad de México", en El perfil de México en 1980, vol. III, México, Siglo XXI.

Corona, C. Reina, Chávez, Ana María, Rossanan, I. y Gutiérrez, M., 1999, Dinámica migratoria de la Ciudad de México, México, Universidad Nacional Autónoma de México, Gobierno del Distrito Federal.

Corona, C. Reina, R., José Luque, G., 1992, “Cambios recientes en los patrones migratorios a la Zona Metropolitana de la Ciudad de México (ZMCM)", en Revista de Estudios Demográficos y Urbanos, vol. 7, núm. 2 y 3, pp. 575-586. 
Díaz-Barriga, Ángel, 1995, Empleadores de universitarios. Un estudio de opiniones, México, CESU/UNAM/PORRÚA.

Echarri, C., y Pérez, J., 2007, “En tránsito hacia la adultez: eventos en el curso de vida de los jóvenes en México, en Revista de Estudios Demográficos Urbanos, vol. 22, núm. 64, pp. 43-77.

Gandini Luciana y Castro, Nina, 2006, "La salida de la escuela y la incorporación al mercado de trabajo en los años de juventud. Análisis de tres cohortes de hombres y mujeres en México", Seminario la dinámica demográfica y su impacto en el mercado laboral de los jóvenes, 28 noviembre, Universidad Autónoma Metropolitana- Xochimilco, México.

Garza, Gustavo, 2003, La urbanización de México en el siglo XX. México, El Colegio de México, Centro de Estudios Demográficos y de Desarrollo Urbano.

Hofferth, S., Reid, L. y Mott, Frank, 2001, "The effects of early childbearing onschooling over time", un Family Planning Perspectives, vol. 33, núm. 6, pp. 259267.

Horbat, Jorge, 2004, "Primer empleo de los jóvenes en México", en Papeles de población, año 10, núm. 42, pp. 199-249.

INEGI, 2000, XII Censo general de población y vivienda, Aguascalientes, Instituto Nacional de Estadística, Geografía e Informática.

Lloyd, C., 2006, "Schooling and adolescent reproductive behavior", in Developing Countries, Nueva York, Population Council.

Lloyd, C., Behrman, J., Lam, D., y Stromquist, N., 2005, "Schooling”, en Lloyd, C. (ed.), Growing up global: the changing transitions to adulthood in developing countries, Washington, The National Academies Press.

Mier y Terán, Marta, 2004, "Pobreza y transiciones familiares a la vida adulta e lasocalidades rurales de la península de Yucatán”, en Población y salud en Mesoamérica, vol. 2, núm. 1.

Muñóz, Christian, 2006, "Cambio demográfico y desarrollo social de los jóvenes", en La situación demográfica de México, México, CONAPO, pp. 89-105.

Muñoz Izquierdo, Carlos, 1996, Diferenciación institucional de la educación superior y mercados de trabajo: seguimiento de egresados de diferentes instituciones a partir de las universidades de origen y de las empresas en que trabajan, México, Asociación Nacional de Universidades e Instituciones de Educación Superior.

Muñoz, H., de Oliveira, Orlandina y Stern, Claudio, 1977, Migración y desigualdad social en la Ciudad de México, México, UNAM-Instituto de Investigaciones Sociales.

Negrete, María Eugenia, 1990, "La migración hacia la Ciudad de México: un proceso multifacético", en Revista de Estudios Demográficos y Urbanos, vol. 5, núm. 3, pp. 641-654.

Oliveira, Orlandina de, 2006, "Jóvenes y precariedad laboral en México", en Papeles de Población, núm. 49, pp. 37-73 
Oliveira, Orlandina de, 1977, "Migración y absorción de mano de obra en la ciudad de México: 1930-1970", en Muñoz, Oliveira y Stern (comps), Migración y desigualdad social en la Ciudad de México, UNAM, El Colegio de México.

Oliveira, Orlandina de, y Mora Salas, Minor, 2008, "Desigualdades sociales y transición a la adultez en el México contemporáneo", en Papeles de Población, año 14, núm. 5, pp. 117-152.

Pérez-Baleón, Guadalupe Fabiola, 2012, "Análisis de la salida de la escuela por cohorte, género y estrato socioeconómico", en Revista de Estudios demográficos y urbanos, vol. 27, núm. 3, pp. 699-737.

Pérez Campuzano, Enrique, 2005, "Reestructuración urbano regional y nuevos derroteros de la migración en la Región Centro de México. El caso de la ZMCM", en Revista de Estudios demográficos y urbanos, vol. 21, núm. 2, pp. 331-367.

Romer, Marta, 2009, ¿Quién soy? Estrategias identitarias entre hijos de migrantes indígenas, México, Instituto Nacional de Antropología e Historia.

Santiago-Hernández, Julio, 2015, "Migración interna y logro ocupacional en la Ciudad de México", en Estudios sociológicos, vol. 33, núm. 98, pp. 337-373.

Santiago-Hernández, Julio, 2012, Migración interna y búsqueda del bienestar: el logro educativo y ocupacional de los migrantes en la Zona Metropolitana del Valle de México, 1980-2009, tesis de doctorado, México, El Colegio de MéxicoCentro de Estudios Sociológicos.

Solís, Patricio, 2012, "Desigualdad social y transición de la escuela al trabajo en la Ciudad de México", en Estudios Sociológicos, vol. 30, núm. 90, pp. 641-680.

Solís, Patricio, 2008, Manual de análisis de supervivencia en stata, México, El Colegio de México, (documento interno).

Solís, Patricio, 2007, Inequidad y movilidad social en Monterrey, México, El Colegio de México.

Solís, Patricio, 2005, "Cambio estructural y movilidad ocupacional en Monterrey”, en Estudios Sociológicos, vol. 23, núm. 1, pp. 43-74.

Solís, Patricio, 1997, "El retiro como transición a la vejez en México", en Rabell, Cecilia (coord.), Los retos de la población, México, FLACSO, Juan Pablo Editores.

Stern, Claudio, 1977, "Cambios en los volúmenes de migrantes provenientes de distintas zonas geo-económicas", en Muñoz, H., de Oliveira, Orlandina y Stern, Claudio (comp.), Migración y desigualdad social en la Ciudad de México. México, UNAM, Instituto de Investigaciones Sociales, El Colegio de México.

UNESCO, 2009, "Educación para todos en el 2015 ¿Alcanzaremos la meta? Educación para todos", en Informe de Seguimiento de La ETP en el mundo, vol. 7.

Villagómez-Ornelas, Paloma, 2008, Maternidad adolescente en México: diversos escenarios de desventaja social, tesis de maestría, México, Facultad Latinoamericana de Ciencias Sociales. 


\section{RESUMEN CURRICULAR DEL AUTOR}

Julio Santiago Hernández

Doctor en Ciencias Sociales con Especialidad en Sociología por El Colegio de México. Maestro en Estudios Urbanos por la misma institución y licenciado en Economía por la Universidad de Guadalajara. Es miembro del Sistema Nacional de Investigadores del Consejo Nacional de Ciencia y Tecnología. Actualmente es profesor-investigador de tiempo completo en la Universidad de Guadalajara en el Centro Universitario Tonalá. Su más reciente publicación de 2017: "Análisis de la duración de las estancias de los migrantes mexicanos de retorno en Estados Unidos" en Memorias del $2^{\circ}$. Encuentro Regional Centro-Occidente del Consejo Mexicano de Ciencias Sociales, 10 y 11 de noviembre de 2016.

Dirección electrónica: julio.santiago@cutonala.udg.mx 